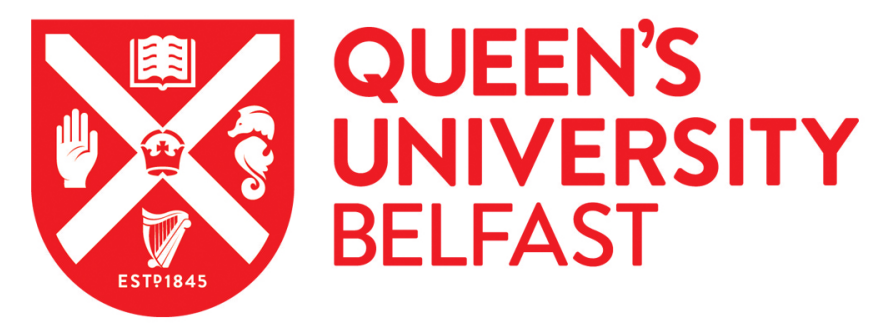

\title{
Passive Mixer cum Reactor Using Threaded Inserts: Investigations of Flow, Mixing, and Heat Transfer Characteristics
}

Khalde, C. M., Ramanan, V., Sangwai, J. S., \& Ranade, V. V. (2019). Passive Mixer cum Reactor Using Threaded Inserts: Investigations of Flow, Mixing, and Heat Transfer Characteristics. Industrial and Engineering Chemistry Research. https://doi.org/10.1021/acs.iecr.9b04606

Published in:

Industrial and Engineering Chemistry Research

Document Version:

Peer reviewed version

Queen's University Belfast - Research Portal:

Link to publication record in Queen's University Belfast Research Portal

Publisher rights

Copyright 2019 ACS. This work is made available online in accordance with the publisher's policies. Please refer to any applicable terms of use of the publisher.

\section{General rights}

Copyright for the publications made accessible via the Queen's University Belfast Research Portal is retained by the author(s) and / or other copyright owners and it is a condition of accessing these publications that users recognise and abide by the legal requirements associated with these rights.

Take down policy

The Research Portal is Queen's institutional repository that provides access to Queen's research output. Every effort has been made to ensure that content in the Research Portal does not infringe any person's rights, or applicable UK laws. If you discover content in the Research Portal that you believe breaches copyright or violates any law, please contact openaccess@qub.ac.uk. 


\section{Passive Mixer cum Reactor using Threaded Inserts: Investigations of flow, mixing and heat transfer characteristics}

Chirag M. Khalde, ${ }^{\text {ab }}$ Vikram Ramanan, ${ }^{\mathrm{c}}$ Jitendra S. Sangwai, ${ }^{\mathrm{a}}$ and Vivek V. Ranade, ${ }^{\mathrm{b} *}$

${ }^{\mathrm{a} G a s}$ Hydrate and Flow Assurance Laboratory, Petroleum Engineering Program,

Department of Ocean Engineering, Indian Institute of Technology Madras, Chennai 600 036, India.

${ }^{\mathrm{b}}$ Multiphase Reactors and Intensification Group (mRING) Bernal Institute, University of Limerick, Ireland and

School of Chemistry and Chemical Engineering, Queen's University Belfast, Belfast BT9 5AG

Northern Ireland, UK

${ }^{\mathrm{c}}$ National Centre for Combustion Research and Development, Indian Institute of Technology Madras, Chennai 600 036, India.

*Corresponding Author:

Vivek V. Ranade: V.Ranade@qub.ac.uk; Vivek.Ranade@ul.ie 


\begin{abstract}
Significant efforts have been and are being spent on developing intensified tubular reactors for continuous manufacturing of fine and specialty chemicals. In this work, we have proposed a new design of passive mixer-cum-reactor for process intensification and development of continuous processes. The mixer/reactor consists of threaded inserts with cone-shaped ends, placed concentrically in the tube such that fluid flows through the annular region between the inserts and the tube. The proposed design is easy to fabricate, maintain, and overcomes the limitations of scale up/scale down compared to most of the commercial passive mixers. The split and recombine of flow around inserts, the swirling effect generated by threads, change in the swirl direction due to change in the direction of screw threads, and pinching effect/expansion at the cone-cone shaped ends realize desired enhancements in mixing and heat transfer. A detailed computational study has been carried out on the mixer-cum-reactor to characterize flow, mixing and heat transfer at different operating conditions using a verified and validated CFD model. Various designs and configurations of threaded inserts were considered: 5-channel, 7-channel and 9-channel, smooth surface (no threading) and smooth surface-extended rear end inserts. The flow, mixing and heat transfer were characterized over the Reynolds number range of 100 to 1600. Structure of the generated swirling flow, effect of pinching/expansion, direction reversal of flow, tracer fraction, temperature and path lines were investigated systematically to gain new insights. Threaded inserts could achieve excellent mixing (>99 \% of mixing intensity) and heat transfer (7 times smooth inserts and 20 times without inserts). The presented results will provide a sound basis for selecting appropriate threaded inserts for intensifying mixing and heat transfer in tubular reactors. The work also provides a useful starting point for further work on multiphase flows in a tubular reactor with threaded inserts.
\end{abstract}




\section{Introduction}

Several research institutes, universities and companies throughout the world have programs based on continuous flow synthesis and manufacturing at various levels. Mixers/Reactors for continuous manufacturing of fine and specialty chemicals have been a hot topic not only in academics but have formed an integral part of variety of industrial processes. Enhanced mixing and heat transfer are primary requirement in many different industrial applications such as: a) Chemical industry: reaction rates, heat exchangers, etc. b) Petroleum industry: formation of homogenous drilling fluids which is a mixture of clay and stabilized oil in water emulsion, production of crude oil, etc. c) Pharmaceutical industry: mixing of different species of drugs, enzymes, etc. d) Paint industry: mixing of multispecies fluids like thinners, blenders, etc. There has been a paradigm shift in approach for manufacturing chemicals by preferring MAGIC (modular, agile, intensified, and continuous) processes over conventional ones. which has resulted into the development of variety of mixers/reactors. ${ }^{1,2}$ Mixers/reactors can be broadly grouped into two classes: a) active: uses moving surfaces to enhance mixing (rotors, vibrations etc.) and b) passive: uses geometrical configuration to enhance mixing and heat transfer. ${ }^{3}$ Several designs and geometric configurations involving folding structures, serpentine channels, splitting and recombining flows and obstruction have been used in passive mixers. ${ }^{4,5}$

Active mixers promote mixing by introducing mechanical energy (in the form of rotation, vibrations, ultrasound, vapor pneumatic power), or dynamic differential pressure, ultrasonic or piezoelectric actuation, magnetic actuation, light energy (through laser irradiations) or through electro-kinetic energy. ${ }^{6-12}$ Although active mixers are capable of providing intense mixing, they often require complicated device actuators and fabrication protocols. Passive mixers are preferred over active devices for process intensification and modular processes, owing to no moving parts, thereby less maintenance; ability to number up; large heat transfer area; high mixing intensity; low pressure drop; cost-effective; compact, robust and simple for manufacturing. Considering several advantages of passive mixers and microfluidic devices having such features, they become the most obvious choice for mixing in modular processes for continuous flow systems.

Several exhaustive reviews are available for classifying different types of passive mixers based on their operating principles, commercialization and applications indicating their importance and implications. ${ }^{3,5,13-}$ ${ }^{19}$ The choice of mixer/reactor type is best determined by the specific application, available space for the device and even the desired level of complexity of design with acceptable fabrication tolerance. The scales at which they operate have been miniaturized for exploiting the increased surface to volume ratio. Many investigators have studied flow and mixing in various components of micro-reactors. ${ }^{14,17,20}$ Many designs of passive mixers are studied over last two decades and are also reviewed to compare the designs, 
performance and flow patterns. ${ }^{21}$ Design of passive micromixers usually aims at increasing the tortuosity along the channel length so as to increase the contact area between the fluid elements and enhance diffusion. ${ }^{22-25}$ Another approach is to use hydrodynamic focusing to achieve better mixing. A third approach is the flow separation and recombination approach that can be achieved through various complex multilayer channel structures, periodic or aperiodic alignment of various segments or objects in the channels, etc. ${ }^{10,26-31}$ Such variations in the flow within the smaller length scales and low Reynolds number lead to transverse flow or even tangential flow to generate chaotic advection. Depending upon the number of channels the fluid stream splits and then combines (i.e., lamination), the mixing rates get enhanced significantly.

Challenges in most of the passive mixer designs are that each of the designs has its operating range and scale at which the best possible performance is achieved. An ideal passive mixer/reactor for realizing modular, agile, intensified and continuous (MAGIC) process is expected to have following characteristics: a) enhanced mixing; b) enhanced heat transfer; c) compact, robust, easy maintenance and high endurance; and d) no dead zones or back mixing. A large number of passive mixers/reactors have been developed/innovated to satisfy the above requirements. Unfortunately, no single mixer reactor design is found to satisfy all of the above requirements for a wide range of operating conditions. Therefore, there is a scope and need for developing novel designs that can overcome all the above limitations. We have reviewed some of the recently developed passive mixers in Table 1. The passive mixers can be classified into four categories based on their geometric configuration: a) Use bends with no change in cross-section of channel/ tube; b) Use varying cross-section of channel/tube; c) Use channel branching for flow split and recombine d) Use inserts to direct the flow in the channel.

In this work, we propose a new patented design of passive mixer which is based on threaded inserts (Figure 1a). ${ }^{32}$ The working principle is discussed in Section 2. A computational study is carried out to understand the flow physics, heat transfer and mixing characteristics of the proposed design. The purpose of this exercise of carrying out single-phase flow simulations is to understand the influence of various geometric and operating parameters on flow characteristics and use the results for designing appropriate experimental setup. Therefore, we conclude that this numerical study is a pre-requisite for establishing the design of the passive mixer/reactor. Preliminary experiments have been carried out for verifying the computational model. The key results of flow, mixing and heat transfer for three different inserts are presented over the Reynolds number up to 1600 . The presented results will be useful for guiding the selection of threaded inserts and will provide a basis for further work on extending applications of threaded inserts for multiphase flow applications. 
Table 1: Quantitative comparison of passive mixer working on geometric modification/variations

\begin{tabular}{|c|c|c|c|c|c|}
\hline Design of passive mixer & Reference/ Design and studies performed & $\begin{array}{l}\text { Re; working } \\
\text { fluid }\end{array}$ & $\begin{array}{c}I_{M(\max )} \\
\%\end{array}$ & $\mathbf{N u} / \mathrm{Nu}_{\text {(pipe) }}$ & Dead zone \\
\hline \multicolumn{6}{|c|}{ Use bends with no change in cross-section of channel/ tube } \\
\hline & $\begin{array}{c}\text { Yoon et al. }{ }^{33} \\
\mathrm{D}=2 \mathrm{~mm} ; \mathrm{Lr}=5-40 \\
\text { Zig-Zag channel with a semicircular cross- } \\
\text { section } \\
\text { (Experimental and numerical) }\end{array}$ & $50-2000$ & - & $1.5-5.2$ & $\begin{array}{l}\text { Yes, } \\
\text { observed } \\
\text { above } \operatorname{Re}= \\
550)\end{array}$ \\
\hline 1111 & $\begin{array}{c}\text { Karale et al. }{ }^{34} \\
\text { Serpentine channels of different radius of } \\
\text { curvatures, with a square cross-section } \\
\left(1 \times 1.5 \mathrm{~mm}^{2}\right) \\
(\text { Experimental and numerical }) \\
\end{array}$ & $133-666$ & - & $\begin{array}{l}1.95-3.46 \\
\text { S-shaped } \\
\text { channel }\end{array}$ & $\begin{array}{l}\text { Yes, } \\
\text { observed for } \\
\text { sharp bend } \\
\text { cases only }\end{array}$ \\
\hline & $\begin{array}{c}\text { Kumar et al. }{ }^{35} \\
\text { Singh et al. }{ }^{36} \\
\mathrm{D}=5.5 \mathrm{~mm}, \mathrm{~L}=3622 \mathrm{~mm} \\
\text { Coiled flow inverter } \\
\text { (Experimental and numerical) }\end{array}$ & $3000-10000$ & - & $1.3-1.5$ & No \\
\hline \multicolumn{6}{|c|}{ Use varying cross-section of channel/tube } \\
\hline & $\begin{array}{l}\text { Wang et al. }{ }^{37} \\
\text { Modified serpentine channel with an } \\
\text { asymmetric lateral wall structure (Numerical) }\end{array}$ & $\begin{array}{r}0.1-100 \\
\text { (water) }\end{array}$ & 80 & - & Yes \\
\hline $\mathrm{d}=5.1 \mathrm{~mm}$ & $\begin{array}{c}\text { Hasabnis et al. }{ }^{25} ; \text { Sharma et al. }{ }^{38} \\
\text { Pinched tube (Experimental and numerical) }\end{array}$ & $\begin{array}{c}10-1060 \\
3000-28000\end{array}$ & 80 & $\begin{array}{c}1.682- \\
1.689\end{array}$ & No \\
\hline
\end{tabular}




\begin{tabular}{|c|c|c|c|c|c|}
\hline$\{-1-1-f \cdot\}$ & $\begin{array}{c}\text { Vicente et al. }{ }^{39} \\
\mathrm{D}=18 \mathrm{~mm} \\
\text { Spirally corrugated tubes } \\
\text { (Experimental) }\end{array}$ & $1100-50000$ & - & $1.5-3.3$ & No \\
\hline (1) & $\begin{array}{c}\text { a) Sparrow and Prata }{ }^{40} \\
\text { b) Prata and Sparrow } \\
41 \\
\text { Symmetric variation in the cross-section along } \\
\text { the length of the circular tube } \\
\text { a) Convergent-divergent channel } \\
\text { b) Wavy channel } \\
\text { (Experimental and numerical) }\end{array}$ & $100-1000$ & - & $\begin{array}{l}\text { a) } 1-1.37 \\
\text { b) } 2.35-5\end{array}$ & yes \\
\hline $\mathrm{nm}$ & $\begin{array}{c}\text { Rafeie et al. }{ }^{42} \\
\text { Threaded lemniscate-shaped micromixer } \\
\text { (Experimental and numerical) }\end{array}$ & $\begin{array}{c}0.001-1000 \\
\text { (water) }\end{array}$ & 90 & - & No \\
\hline $\mathrm{d}=19-22 \mathrm{~mm} ;$ pitch $=25-9 \mathrm{~mm}$ & $\begin{array}{l}\text { a) Cauwenberge et al. } .^{43} \text { (air); } \\
\text { b) Kareem et al. } .^{44} \text { (water) } \\
\text { Helically or spirally corrugated Tubes } \\
\text { (Numerical+ experimental) }\end{array}$ & $\begin{array}{l}\text { a) } 100-10^{5} \text { (air); } \\
\text { b) } 100-1300 \\
\text { (water) }\end{array}$ & - & $\begin{array}{l}\text { a) } 1-2.8 \\
\text { (air); } \\
\text { b) } 0.98- \\
2.66 \\
\text { (water) }\end{array}$ & Yes \\
\hline \multicolumn{6}{|c|}{ Use channel branching for flow split and recombine } \\
\hline inlet & $\begin{array}{c}\text { Costa et al. }{ }^{45} \\
\text { Micro-Meso } \\
\text { Structured cell network } \\
\text { (Experimental and numerical) }\end{array}$ & $\begin{array}{c}10-1000 \\
\text { (water) }\end{array}$ & - & $\begin{array}{c}2-30(\mathrm{Nu} \\
\text { only) }\end{array}$ & Yes \\
\hline
\end{tabular}




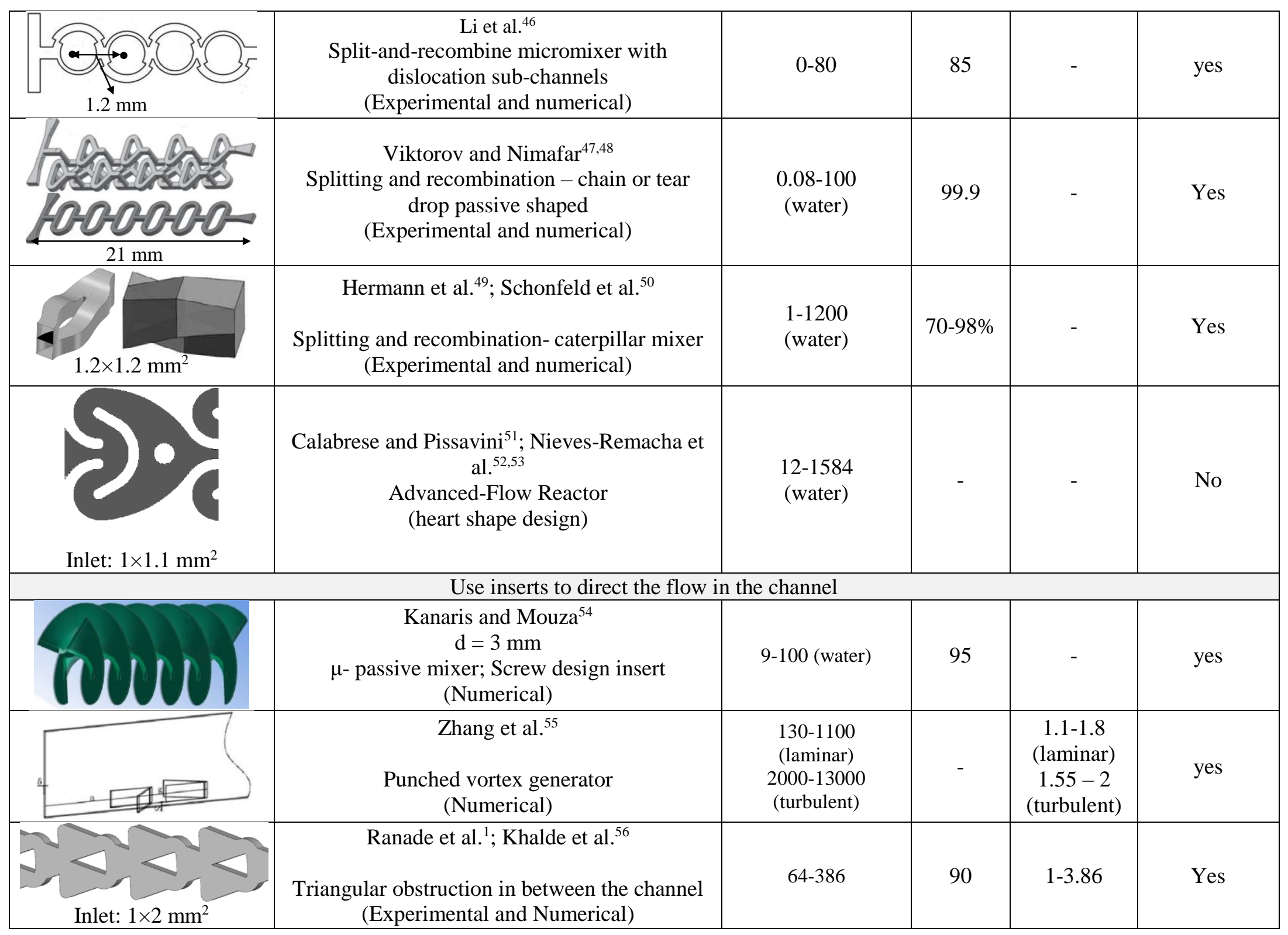




\begin{tabular}{|c|c|c|c|c|c|}
\hline & $\begin{array}{c}\text { Jung et al. }{ }^{57} \\
\text { Barrier-Embedded Partitioned Pipe Mixer } \\
\text { (Numerical) }\end{array}$ & 0.1 & 99.9 & - & yes \\
\hline $\mathrm{t}_{\text {insert }}=4 ; \mathrm{d}_{\mathrm{pipe}}=13.6 ; \mathrm{L}_{\mathrm{pipe}}=186$ & $\begin{array}{c}\text { Stec and Synowiec } \\
\text { Kenics and Koflo static mixer consisting of } \\
\text { inserts placed within the pipe } \\
\text { (Experimental and Numerical) }\end{array}$ & $800-4200$ & $>98$ & - & yes \\
\hline
\end{tabular}

Note: The examples cited in this table are to classify the passive mixers and not to provide a detailed review of passive mixers/reactors. 


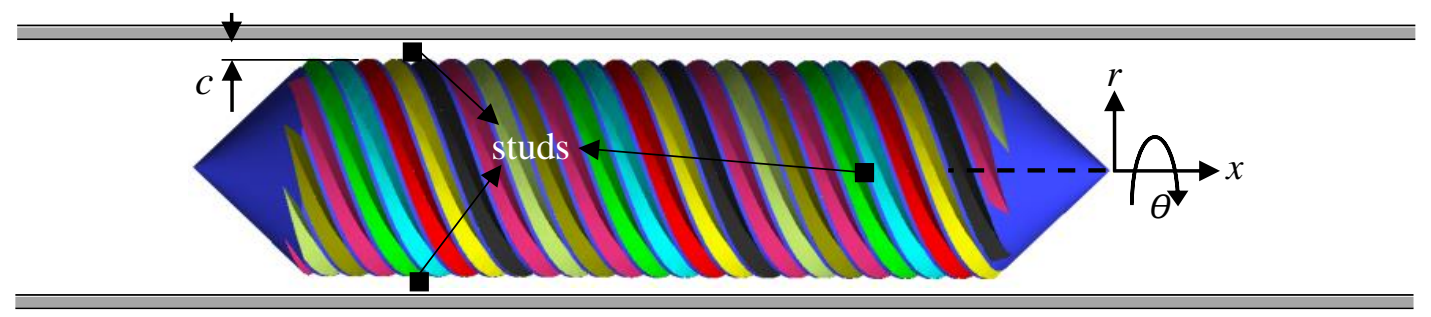

(a)

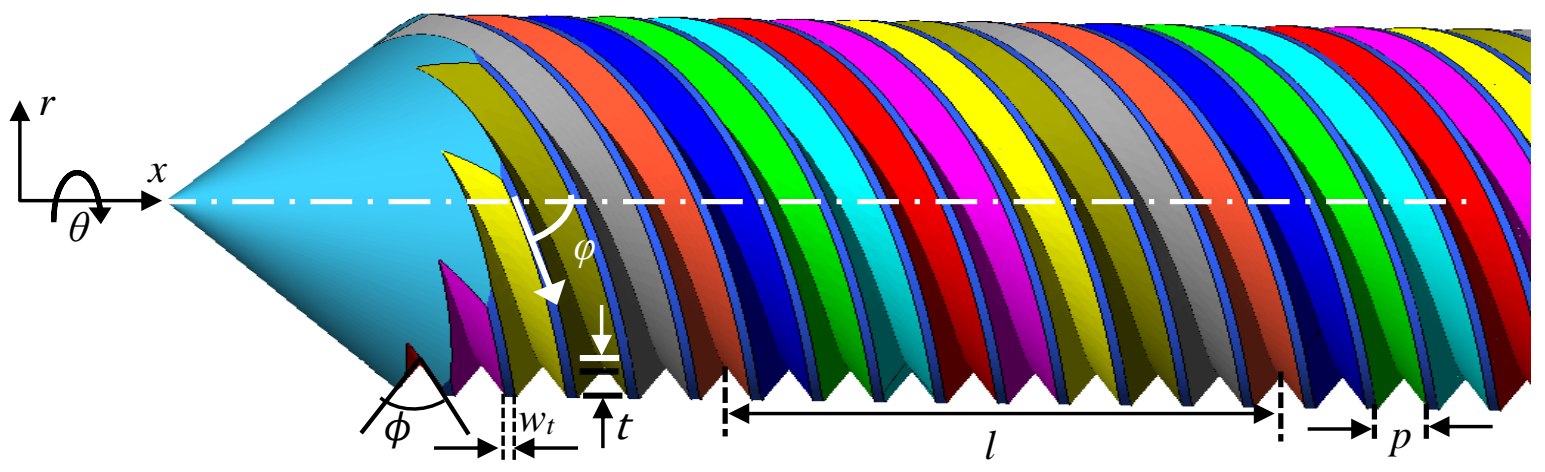

(b)

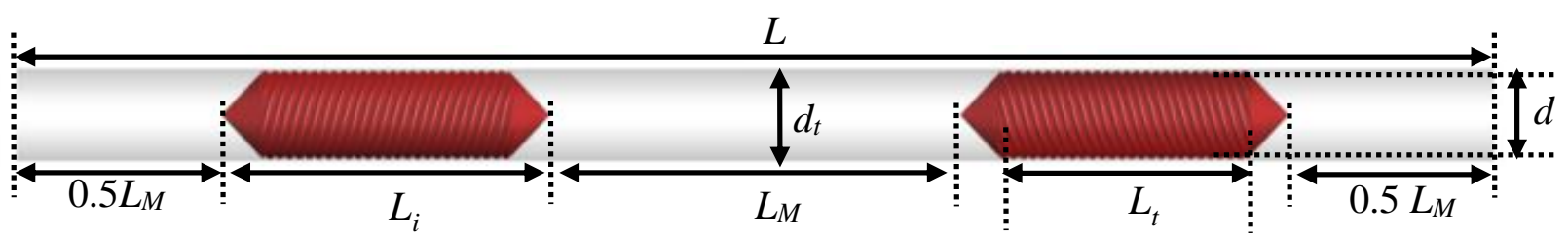

(c)

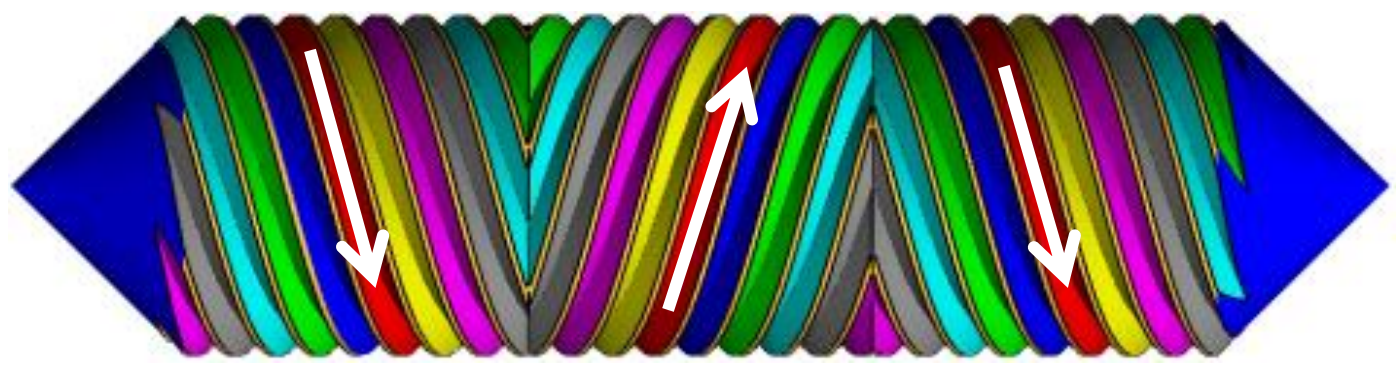

(d) 


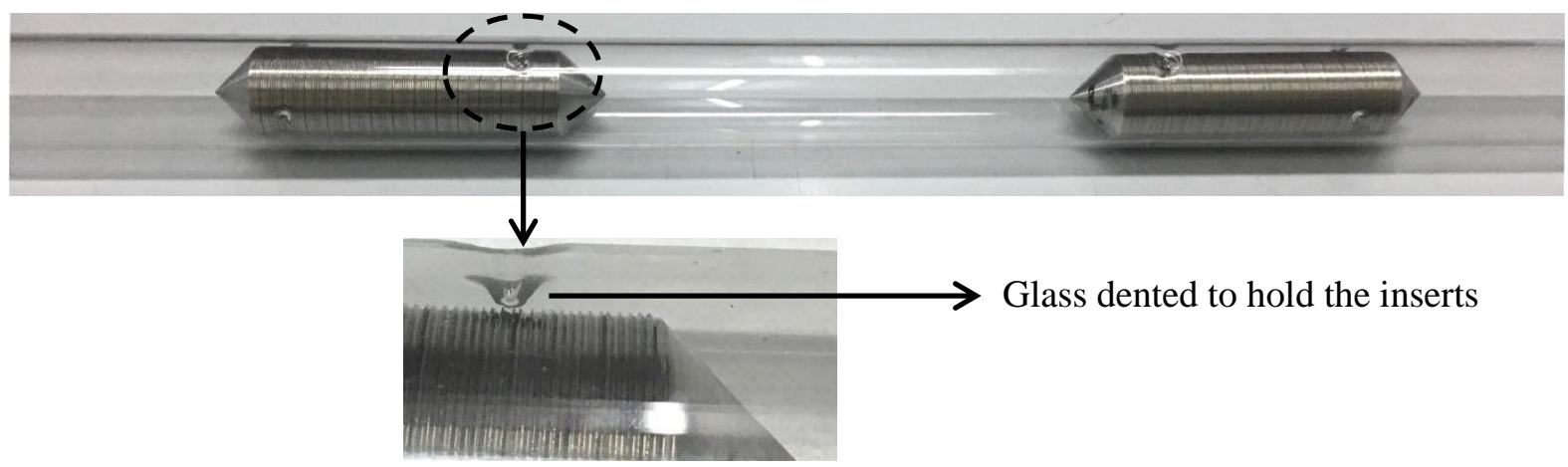

(e)

Figure 1: Design details of threaded insert passive mixer. ${ }^{32}$

(a) Unidirectional threaded passive mixer mounted within the pipe using studs; (b) Geometric details of threaded insert; (c) Domain details of periodic computational domain consisting of two inserts of opposite threading; (d) Schematic of single unit of threaded insert with opposite threading; (e) Unidirectional threaded insert mounted within the glass tube using glass blowing technique

\section{Design details and working principle of passive-mixer-cum-reactor with inserts}

The schematic of a multiple threaded insert placed within a pipe has been shown in Figure 1a. A detailed schematic of the configuration with two inserts having opposite direction threading is included as Figure $\mathrm{S} 1$ in the Supplementary information (SI). The multiple threaded insert is held within the tube with the help of four studs placed on the ends of the insert: Two studs mounted on both the ends of the insert on both $x$ and $r$ planes as shown in the Figure 1a (three of the studs are visible in the figure whereas the fourth one is on the rear side). Details of the mounting of the insert in the pipe are shown in Figure S2 of SI. Regarding the geometric details of the design, pipe diameter (1 inch) was selected rather arbitrarily as there needs to be a starting point for developing a workable design. Most of the other key characteristic dimensions of the device are based on either prior experience or preliminary numerical experiments. Prior experience of application of screw inserts for rheometer (Sangwai and Khalde ${ }^{59}$ and Pandey et al. ${ }^{60}$ ) was useful and guided some of the selections. Explanations for selection of few of the dimensions are discussed below:

- The clearance between the pipe and the inserts is around $1 \mathrm{~mm}$. This value was selected based on viscometer design, which was primarily used for generating a shearing environment (inner body rotating and outer body stationary).

- The angle of the V-thread of $60^{\circ}$ was selected based on standards recommended by the National Bureau of Standards. ${ }^{61}$

- We numerically investigated configurations with a different numbers of channels (from 1channel to 9-channel design [an odd number of channels were considered]). The 
performance was found to improve with an increase in the number of channels. In this manuscript, we have reported the results for 5-channels, 7- channels, and 9-channels which exhibited better performance (discussed later).

The concentrically mounted insert splits in the radial direction. Smooth splitting and recombination of flow streams are ensured by using the conical ends of the insert. The fluid flowing through this apparatus also experiences a pinching effect in the near-nose region and flow smoothly passed at the aft end without the generation of any backflow or secondary vortices. The fluid flowing through the wall-insert clearance gets resolved into two fluid streams, one flowing through the clearance between the insert and the pipe wall and one flowing through the threads of the insert. Fluid flows through the clearance experiences a shearing effect, forcing the fluid to shear in the direction of the threading (in $\theta$ direction) due to the undercurrent of the fluid stream flowing through the channel.

This design consists of combination of different types of passive mixers discussed in Table 1, i.e., a) Use bends with no change in cross-section of channel/ tube: Each thread of the multi-threaded insert acts as a virtual channel; b) Use varying cross-section of channel/tube: The area variation is due to the conical ends of the insert; c) Use channel branching for flow split and recombine: The conical insert ends allows the flow to split and later merge aft of the insert; d) Use inserts to direct the flow in the channel. Figure $1 \mathrm{~b}$ shows the geometric parameters of the insert along with their dimensions in Table 2. The geometric parameters which govern the flow dynamics and their impact on flow physics are discussed below:

1. Conical ends of the inserts: The fluid flowing through the pipe splits radially in $r$ direction away from the pipe axis due to the presence of the insert. The ends of the insert, i.e., the nose and aft part of the insert is conical to ensure a smooth transition of flow split (nose side) and recombine (aft side).

2. Angle of the conical ends of the inserts $(\psi)$ : Increase in the cone angle will increase the bluntness of the insert resulting in significant pressure drop and formation of secondary vortices. Reduced cone angle will increase the contact surface of the fluid resulting in a higher pressure drop. Therefore, an appropriate cone angle needs to be identified for ensuring low energy dissipation and smooth flow of fluid. The fluid flowing over the conical ends experiences a pinching effect and expansion effect in the near-nose region and aft region, which enhances mixing.

3. Number of channels $(\boldsymbol{n})$ : The number of channels (or threading) defines the angle $\phi$ of the generated channel is, with respect to the axis of the pipe. The generated over the insert generates an angle $\phi$ to the fluid flowing over it. A highly steep angle (say $\geq 85^{\circ}$ for single channel) will result 
in derailment of the fluid from the channel, whereas for lesser values of $\phi$, i.e., higher number of channels, the fluid will follow the channels thereby improving the shearing of the fluids within the clearance.

4. Depth $(t)$ of the channel/thread and clearance $(c)$ : The fluid flow over the multi-threaded insert splits into two components, one flowing through the channel and the other through the clearance. An appropriate ratio of the depth and the ratio of depth to clearance will ensure enhanced shearing and contact of the two flow streams. (Figure 1a-b)

5. Type of threading: The type of threading dictates the mass flow through the channel and the fluidsolid contact region. Therefore, the energy dissipation (or the pressure drop) and heat transfer are governed by the type of threading. Different types of threading options are available for generating channels over the insert. For example: Buttress thread, Whitworth thread, V-thread, square thread, etc. The scope of this study has been limited in this work to V-thread form.

6. Width of the thread/channel ( $p)$ : Increase in the width of the channel results in higher mass flow through the channel.

7. Angle of the thread/channel $(\phi)$ : Higher angle of the thread will result in the derailing of the fluid stream flowing through the channel, whereas a smaller angle will reduce the mass flow through the channel. Therefore, an optimum angle needs to be used to strike a balance.

8. Thread reversal of the insert: The direction of the threads formed over the insert surface is reversed, which will improve the interaction of fluid parcels between the channel and clearance in the region of reversal, consequently result in enhanced mixing. (Not in the scope of this study, Figure 1c).

9. Distance between subsequent threaded units $\left(\boldsymbol{L}_{M}\right)$ : The mixing zone, i.e., the region between the subsequent threaded units, assists in switching the direction of flow streams, thereby establishing uniformity of the flow properties of the two fluid streams, i.e., the channel stream and the clearance stream. (Figure 1d)

10. Switching the threading direction of insert units: The fluid flows past the first unit, swirls are generated in the mixing zone in the direction of the threading of the insert. The pressure distribution developed on the nose side of the second unit having reverse threading hampers the swirl strength and straightens the flow. This enhances mixing and ensures the intermingling of the independent flow streams through channels and clearance. (Figure 1c)

11. First contact of reagents: The reactants/reagents may be introduced at different axial locations within the device: near the nose region of the insert, in the clearance region, or between the mixing zone region where swirling flow exists. (Not in the scope of this study, Figure 1A and Figure 1E of PCT document ${ }^{32}$ ) 
The proposed design of the passive mixer can be manufactured or 3D printed in any material as per the requirement of the process and scale of the design. The design offers an easy to fabricate tubular reactors with intense mixing, heat and mass transfer capabilities. A sample of a stainless steel 306 inserts mounted in a glass sleeve of 1-inch diameter has been shown in Figure 1e. The threading over the insert has been done with a lathe machine. The inserts have been placed concentrically within the glass tube by using glassblowing technique. Four dents have been made after heating the glass and softening it in the region where studs are located (Figure 1e). A detailed numerical study is carried out to establish the operating range, capabilities, and limitations of the proposed design, if any. These results are discussed in Section 4 after the description of the computational model.

Table 2: Dimensions of the studied design

\begin{tabular}{|l|l|l|}
\hline Notation & Geometric parameters & Value $(\mathbf{m m} / \mathbf{d e g r e e})$ \\
\hline$r, \theta, z$ & Cylindrical coordinates & - \\
\hline$d_{t}$ & Internal diameter of the pipe & 25.4 \\
\hline$d$ & Total diameter of the insert $\left(0.952 d_{t}\right)$ & 24.18 \\
\hline$d_{m}$ & Mean diameter of the insert & 23.68 \\
\hline$t$ & Depth of the thread/channel & 2.5 \\
\hline$c$ & Clearance between the insert and pipe & 0.61 \\
\hline$\psi$ & Cone angle of the ends of the insert & $90^{\circ} ; 60^{\circ}$ \\
\hline$\phi$ & Angle made by the V-thread & $60^{\circ}$ \\
\hline$\varphi$ & Angle of the thread with respect to pipe axis $\left(\tan ^{-1}\{\mathrm{~d} / 0.5 l\}\right)$ & $72.8^{\circ} ; 66.5^{\circ} ; 60.8^{\circ}$ \\
\hline$w_{t}$ & Distance between consecutive thread/channels & 0.5 \\
\hline$p$ & Pitch or width of the thread or pitch & 2.5 \\
\hline$n$ & Number of threads/channels on multi-threaded insert & $5,7,9($ dimensionless) \\
\hline$l$ & Axial advance of thread for one complete turn of $360^{\circ}\left(\mathrm{n}\left\{p+w_{t}\right\}\right)$ & $15 ; 21 ; 27$ \\
\hline$L_{t}$ & Length of the threaded part of the insert $(3 d)$ & 72.54 \\
\hline$L_{i}$ & Length of the insert $(4 d / 4.5 d)$ & $96.72 ; 108.81$ \\
\hline$L_{M}$ & Distance between two consecutive insert units $(5 d)$ & 120.9 \\
\hline$L$ & Total length of the considered periodic pipe domain $(18 d)$ & 435.25 \\
\hline$L_{D}$ & Periodic domain consisting of a single insert $(9 d)$ & 217.63 \\
\hline
\end{tabular}

\section{Computational Model}

The proposed passive mixer design with inserts has been computationally simulated for different insert designs. Due to a large number of geometric parameters of the design, it is vital to know the effect of these parameters of flow dynamics for freezing a configuration providing required performance, and to be used for carrying out further experimental studies. Five configurations viz., 5-channel, 7-channel, 9-channel, smooth surface (no threading) and smooth surface-extended rear end inserts have been studied here. The numerical verification of the computational model and grid independence studies were carried out on one 
of the configurations. Steady state Navier-Stokes equation was used for establishing the flow dynamics and heat transfer characteristics within the selected domain. From simulation studies, we observe that the presence of studs, over which the inserts are mounted, have a negligible effect over the flow characteristics and have been neglected in the carried comparative studies for the selected configurations (these results have been discussed later). The details of the implemented model equations, boundary conditions, postprocessing methodology, and details of the numerical solution are as follows:

\subsection{Model equations}

The governing equations, viz., continuity, momentum and energy balance equations have been solved for simulating the flow, mixing and heat transfer in the selected configurations. ${ }^{62}$

$\nabla \cdot \boldsymbol{u}=0$

$(\boldsymbol{u} \cdot \nabla) \boldsymbol{u}=\frac{1}{\rho} \nabla P+\vartheta \nabla^{2} \boldsymbol{u}$

$\nabla \cdot\left[\boldsymbol{u}\left(E+\frac{P}{\rho}\right)\right]=\frac{\nabla}{\rho}[k \nabla \mathrm{T}+(\overline{\bar{\tau}} \cdot \boldsymbol{u})]$

where $\boldsymbol{u}$ is the velocity vector $(\mathrm{m} / \mathrm{s}), \rho$ is the density of the fluid $\left(\mathrm{kg} / \mathrm{m}^{3}\right), P$ is the pressure $\left(\mathrm{N} / \mathrm{m}^{2}\right), \vartheta$ is the kinematic viscosity of the fluid $\left(\mathrm{m}^{2} / \mathrm{s}\right), E$ is the total energy per unit mass $(\mathrm{Nm} / \mathrm{kg}), k$ is thermal conductivity (W/m.k) $T$ is the temperature $(K)$ and $\overline{\bar{\tau}}$ is the viscous dissipation or the stress tensor $\left(\mathrm{N} / \mathrm{m}^{2}\right)$.

Multispecies transport equation has been used for carrying out multispecies flow in the passive mixer cum reactor. $^{62}$

$(\boldsymbol{u} \cdot \nabla) m_{i m}=D_{i m} \nabla^{2} m_{i}$

where $m_{i}$ is the mass fraction of the tracer of species $i$ and $D_{i m}$ is the mass diffusion coefficient of species $i$ in the mixture. The density and kinematic viscosity of the fluid and mass diffusivity of tracer in mixture were constant.

\subsection{Configurations of the selected insert designs and boundary conditions}

As discussed in design details section, there are a number of design parameters over which the performance of the mixer-cum-reactor depends upon. Two units of inserts of opposite threading direction have been placed at a defined distance concentrically within the tube. The geometric and dimensions details of the domain and inserts have been discussed in Figure 1 and Table 2. Five different variants of designs have 
been selected based on modification in the insert surfaces, i.e., 5-channel, 7-channel, 9-channel, smooth surface (no threading) and smooth surface-extended rear end inserts (Figure 2). These designs have been simulated for investigating the flow, mixing and heat transfer over the selected range of Reynolds number. For mounting the inserts within the pipe, four studs have been used such that they cause negligible variation in the flow properties. Simulation results for all the above cases have been explained in the results section.

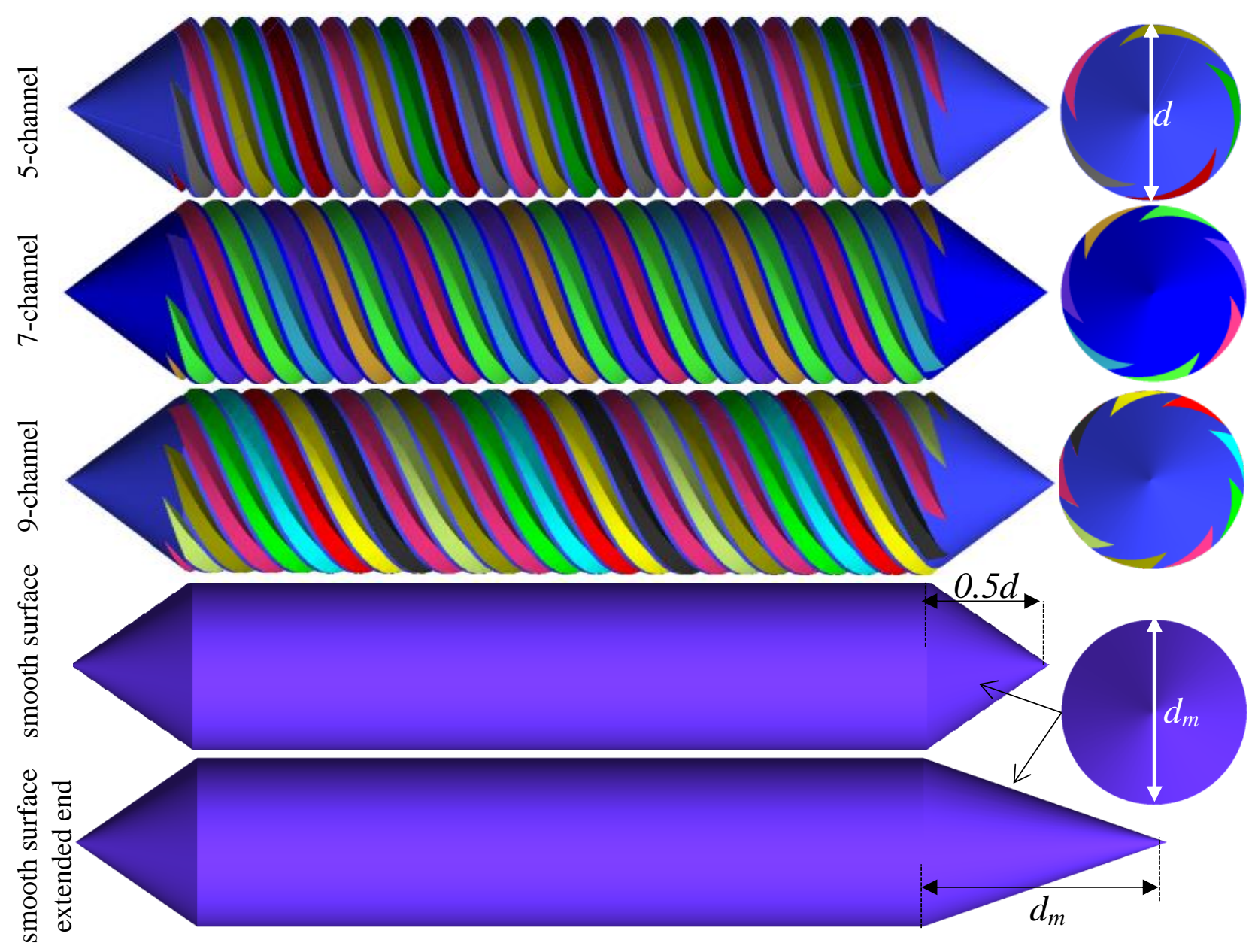

Figure 2: Different variants of the insert designs studied in the present work

Periodic mass flow boundary condition has been imposed over the ends of the tube. Reynolds number is calculated using hydraulic diameter $\left(D_{H}=V_{R} / A_{W}\right.$, where $V_{R}$ is the volume of the reactor/mixer and $\mathrm{A}_{\mathrm{W}}$ is the surface area in contact with the fluid) and the velocity based on hydraulic diameter for the defined mass flow rate. For heat transfer simulations, the pipe surfaces are elevated at a temperature of $380 \mathrm{~K}$, whereas the inlet temperature is maintained at $300 \mathrm{~K}$. In order to arrive at the mixing characteristics of the selected designs, multi-species flow has been simulated. The initially converged solution obtained from steady state laminar flow and heat transfer studies have been used as the initial condition for this study. The periodic inlet surface was split into two equal parts and defined as inlet velocity. Each part allows water and tracer 
(having fluid properties the same as water) to flow into the apparatus. The periodic outlet surface is defined as pressure outlet surface. The velocity through both the inlets was set to equal values such that the total mass flow rates through outlet were the same as corresponding to flow and heat transfer simulations. Water was used as the working fluid of constant density $(\rho)$ of $1000 \mathrm{~kg} / \mathrm{m}^{3}$, dynamic viscosity $(\mu)$ of $0.001 \mathrm{~kg} / \mathrm{m} . \mathrm{s}$ and thermal conductivity of $0.6 \mathrm{~W} / \mathrm{m} . \mathrm{K}$. For mixing studies, the defined secondary fluid tracer was assumed to have the same properties as that of water with mass diffusivity $\left(D_{\mathrm{km}}\right)$ of $2 \times 10^{-9} \mathrm{~m}^{2} / \mathrm{s}$.

\subsection{Quantitative parameters used in the study}

The pressure drop across the considered periodic domain consisting of two threaded inserts for the selected configurations was calculated from these simulations. The geometric details and nomenclature of the studied configurations have been discussed previously in Table 1. The key parameters for the simulations are defined as:

$R e=\frac{\rho u_{H} D_{H}}{\mu}[-] ;$ where $D_{H}=\frac{4 V_{R}}{A_{W}}[m]$ and $\dot{m}=\rho \times \frac{\pi}{4} D_{H}^{2} \times u_{H}\left[\frac{\mathrm{kg}}{\mathrm{s}}\right]$

$\frac{\Delta P}{L}=\frac{2 f \rho u_{H}^{2}}{D_{H}}\left[\frac{N}{m^{3}}\right]$

$P o=f R e[-]$

$E u=\frac{\Delta P}{\rho u_{H}{ }^{2}}$

where $R e$ is the Reynolds number, $D_{H}$ is the hydraulic diameter $(m), V_{R}$ is volume of the reactor $\left(m^{3}\right), A_{W}$ is total area of surfaces in contact with fluid $\left(\mathrm{m}^{2}\right), u_{H}$ is superficial inlet velocity of fluid based on hydraulic diameter and mass flow rate $(\mathrm{m} / \mathrm{s}), \rho$ is density $\left(\mathrm{kg} / \mathrm{m}^{3}\right), \mu$ is dynamic viscosity $(\mathrm{kg} / \mathrm{m} . \mathrm{s}), L$ is the total length of the periodic domain consisting of two units of inserts $(m), f$ is the Fanning frictional factor, Po is Poiseuille number which is independent of fluid material properties, velocity, temperature, or duct size, $E u$ is the Euler number expressing the relationship between a local pressure drop caused by a restriction and the kinetic energy per volume of the flow.

Energy dissipation can be calculated in terms of pressure drop or using the product of stress and strain as:

$\varepsilon=\frac{\Delta P \times q}{M}=\left[\frac{m^{2}}{s^{3}}\right]$ 
$\tau_{i j} \frac{\partial v_{i}}{\partial x_{j}}=\mu\left(\frac{\partial v_{i}}{\partial x_{j}}+\frac{\partial v_{j}}{\partial x_{i}}\right) \frac{\partial v_{i}}{\partial x_{j}}=2 \mu\left[\left(\frac{\partial u}{\partial x}\right)^{2}+\left(\frac{\partial v}{\partial y}\right)^{2}+\left(\frac{\partial w}{\partial z}\right)^{2}\right]+\mu\left[\left(\frac{\partial u}{\partial y}+\frac{\partial v}{\partial x}\right)^{2}+\left(\frac{\partial v}{\partial z}+\frac{\partial w}{\partial y}\right)^{2}+\right.$

$\left.\left(\frac{\partial w}{\partial x}+\frac{\partial u}{\partial z}\right)^{2}\right]$

where $q$ is the volume flow rate through the reactor $\left(\mathrm{m}^{3} / \mathrm{s}\right), \tau_{i j}$ is the stress tensor $\left(\mathrm{N} / \mathrm{m}^{2}\right)$ and $\frac{\partial v_{i}}{\partial x_{j}}$ is the strain tensor $(1 / \mathrm{s}) ; u, v$ and $w$ are velocity components $(\mathrm{m} / \mathrm{s})$ in $x, y$ and $z$ direction.

The Nusselt number $(\mathrm{Nu})$ was calculated as:

$\dot{Q_{\text {in }}}=\dot{m} C_{P}\left(T_{\text {in }}-T_{\text {out }}\right)=h_{\text {avg }} A_{H} \Delta T_{L M T D}$

$\Delta T_{L M T D}=\frac{\left(T_{\text {in }}-T_{\text {out }}\right)}{\ln \left(\frac{T_{W}-T_{\text {in }}}{T_{\text {W }}-T_{\text {out }}}\right)}$

$N u=\frac{h_{a v g} D_{H}}{k}$

Where, $\dot{Q}_{\text {in }}$ is the heat input to the fluid through the wall $(\mathrm{Nm} / \mathrm{s}), \dot{m}$ is the mass flow rate of the fluid $(\mathrm{kg} / \mathrm{s})$, $C_{P}$ is the specific heat at constant pressure of the fluid $(\mathrm{Nm} / \mathrm{kg} . \mathrm{k}), A_{H}$ is a heated pipe wall area $\left(\mathrm{m}^{2}\right), \Delta T_{L M T D}$ is mean logarithmic temperature difference $(K), h_{a v g}$ is convective heat transfer coefficient, $T_{w}$ is the wall temperature $(K), T_{\text {in }}$ and $T_{\text {out }}$ are inlet and outlet temperatures $(K)$.

The heat transfer enhancement ratio $(\eta)$ or Performance evaluation criteria (PEC) is used for comparing the performance of any passive mixer/reactor (insert design in our case) with the corresponding plain (smooth) surface pipe. $\eta$ takes both heat transfer and pressure loss characteristics into account to give a quantitative comparison of different passive mixers and is defined as the ratio of heat transfer to pumping power. Evaluation and quantification of different mixers using a very broad and universal set of criteria are impractical. Therefore, some of the parameters/variables are constrained based on the intended primary objective of the evaluation. In our study, we have used objective functions and constraints as: a) same inlet diameter of the device/smooth pipe; b) same length of the device/smooth pipe; and (c) same pumping power required for the device/smooth pipe operation for reduced flow rates. The derivation for the arrived formula can be referred in Webb and $\mathrm{Kim}^{63}$, and Saha et al. ${ }^{64}$. The formula has been commonly used for evaluation of reactor designs where both heat transfer and pumping power are to be considered. ${ }^{25,65,66}$

$$
\eta=\frac{N u / N u_{\text {pipe }}}{\left(f / f_{\text {pipe }}\right)^{1 / 3}}
$$


where, $N u$ is the Nusselt number and $f$ is the frictional factor.

Mixing realized within the mixer was quantified by evaluating mixing intensity $\left(I_{M}\right)$. The mixing intensity based on the obtained time history of the mass tracer at the outlet was defined as:

$I_{M}=1-\sqrt{\frac{\sigma^{2}}{\sigma_{\text {max }}^{2}}}$ where $\sigma^{2}=\frac{1}{|A|} \int_{A}\left(m_{k}-\bar{m}\right)^{2} d A$

where $\sigma^{2}$ is the variance $\left(\mathrm{kg}^{2}\right), A\left(\mathrm{~m}^{2}\right)$ is the area of the selected monitored surface and $\bar{m}$ is the average mass fraction $(\mathrm{kg} / \mathrm{kg})$ of the reference surface (inlet).

\subsection{Computational details, Grid independency, Model verification, and Validation}

The flow, mixing and heat transfer characteristics have been predicted by numerically solving the governing equations, i.e., mass, momentum and energy (Equations 1-4) using finite volume method using a commercial CFD code FLUENT (Ansys Inc., version 15.0). ${ }^{67}$ These governing equations are spatially discretized using second order upwind schemes. Second order discretization scheme was used for the interpolation of pressure. SIMPLE algorithm has been employed solving the Navier Stokes equations. Absolute value of the root mean square residuals for velocities and mass were ensured to be below $10^{-6}$ and residuals for the energy equation to be below $10^{-10}$ to ensure convergence. Other than this check, monitor points were placed at critical regions and flow sensitive parameters were monitored (static pressure and temperature) to ensure a stabilized steady state solution. For mixing simulations, mass fraction of the tracer $\left(m_{i}\right)$ and variance $\sigma^{2}$ were defined using User Defined Function and were monitored at the outlet periodic surface to establish convergence.

Due to the complexity of the geometry, mainly in the threaded region, and clearance region between the insert and pipe, generating a structured grid is extremely difficult and time-consuming. Therefore, unstructured grid was used for carrying out the simulations. The geometry of the 3D model is developed in AutoCAD software ${ }^{68}$ and later transferred to ICEM CFD ${ }^{67}$ for geometric cleanup and generation of surface mesh consisting of triangular elements. The high-quality surface mesh is later used to generate volume mesh in ANSYS Fluent. ${ }^{67}$ Tetra elements have been used for the volume mesh. Density blocks have been placed near the walls/critical regions to generate high-quality refined grid elements, and coarser in the remaining regions. Key parameters like skew, aspect ratio and Jacobean were used as per the standards. ${ }^{69}$ Mesh details along with a zoomed view to the mesh in the critical regions are shown in Figure S1 and S2 of supplementary information (SI) for the 5-channel and 9-channel design.

As numerical diffusion is inversely related to the resolution of the mesh, highly refined grids were used for carrying out the simulations. Grid independence tests were performed using four grids of count 7.8 million, 14.5 million, 17.5 million, and 21 million elements at $\mathrm{Re}=800$ for 5-channel design. The variation in 
pressure drop was less than $1.5 \%$ compared to the finest grid (Figure S3 in SI). A comparison of the velocity profile has been made in the mixing region aft of the insert at $x / L=0.75$. Insignificant variation in the velocity magnitude is observed for considered grids of the highest number of elements (Figure S4 of SI). The grid size of 21 million was chosen for carrying out further simulations. For verification of the numerical simulations, the energy dissipation calculated based on the pressure drop was compared with the product of stress and strain (Equation 9-10). We observe that the difference between these two approaches is found to be less than $9 \%$. In addition, straight pipe laminar flow and heat transfer simulation was carried out at $R e=400$. The theoretical Nusselt number (3.66) and frictional factor (i.e., $f=64 / R e$ ) were found to be in good agreement with the theoretical model and experiments with less than $1 \%$ difference. ${ }^{70}$ Experiments were carried out to measure the pressure drop across the inserts. The experimental procedure is described in SI. Threaded inserts of different channels were machined in the conventional lathe machine and mounted in a glass tube using a blowing technique (Figure S5). 5-channel inserts were selected for carrying out the validation studies using water as the working fluid. The diameter of the pipe used in the experimental setup is $26 \mathrm{~mm}$. Therefore, simulations were performed using a $26 \mathrm{~mm}$ diameter tube for different $R e$ for validation purposes. Grid of 23.6 million cells was generated using the same methodology and techniques as discussed previously. The results are shown in Figure S6. A good agreement was observed in simulations and experiments. The verified and experimentally validated computational model was then used to investigate key flow, heat transfer and mixing characteristics of threaded inserts.

\section{Results and Discussion}

\subsection{Flow characterization}

Laminar flow was simulated in a periodic domain of threaded mixer for Re ranging from 100 to 1600 . As fluid flows through the mixer-cum-reactor, the threading present over inserts causes the fluid to divert in the direction of the generated channels. Therefore, there is a strong shearing effect in the annulus formed between the insert and the pipe. The inserts are mounted within the pipe with the help of studs. A comparative study was carried out to study the possible influence of studs on flow at $R e=800$ for 5 -channel design. At the stud location, reduction in cross-sectional area in the direction of flow (in $x$-direction) is observed to be less than $2 \%$ compared to the case without studs. Negligible variation in the flow behavior was observed with and without studs, along with an insignificant rise in pressure drop (3\%) due to the presence of studs. Path lines due to the presence of studs do get obstructed, but straighten up in the annular region due to the longer annular region ahead. (Figure S7 of SI). Any obstruction effects on flow are observed to die out quickly as the flow progresses through the annulus region, resulting in an unaffected net flow field past the studs. Therefore, for simplification of the computational model, the studs were not considered in subsequent simulations. 
Stream traces colored by velocity magnitude (non-dimensional with respect to inlet velocity) obtained for 5-channel design at $R e=400$ are shown in Figure 3. Fluid is forced to swirl in the direction of the threading of the threaded inserts (see path lines shown in Figure 3a). Due to a reduction in the area between the annulus, higher velocity magnitudes are observed. The cross-flow between the stream traces following the channel path and the stream traces flowing through the annulus generates strong shearing effects, which enhances mixing in the annulus region. This shearing effect results in the deflection of the stream traces away from the axial direction, i.e., in $\theta$ direction. An isometric view of the velocity magnitude colored stream traces is shown over the whole domain in Figure 3b. Due to the conical shape of the threaded member, the tendency to form secondary vortices is suppressed at both ends. The stream traces are observed to be smoothly converging towards one another as they enter the annulus region and expand at the aft. The swirling induced by the threaded inserts continues in the pipe region (the region between two inserts) which further enhances mixing. Velocity vector field over the cut plane aft of both the inserts is shown in Figure 4 to visualize the swirling effect. Switching of the flow direction can be seen in both these planes shown aft of the inserts due to the change in the threading direction. The switching and deflection of the stream traces unlike threaded inserts, are not observed for unthreaded inserts (smooth surface design shown in Figure 2).
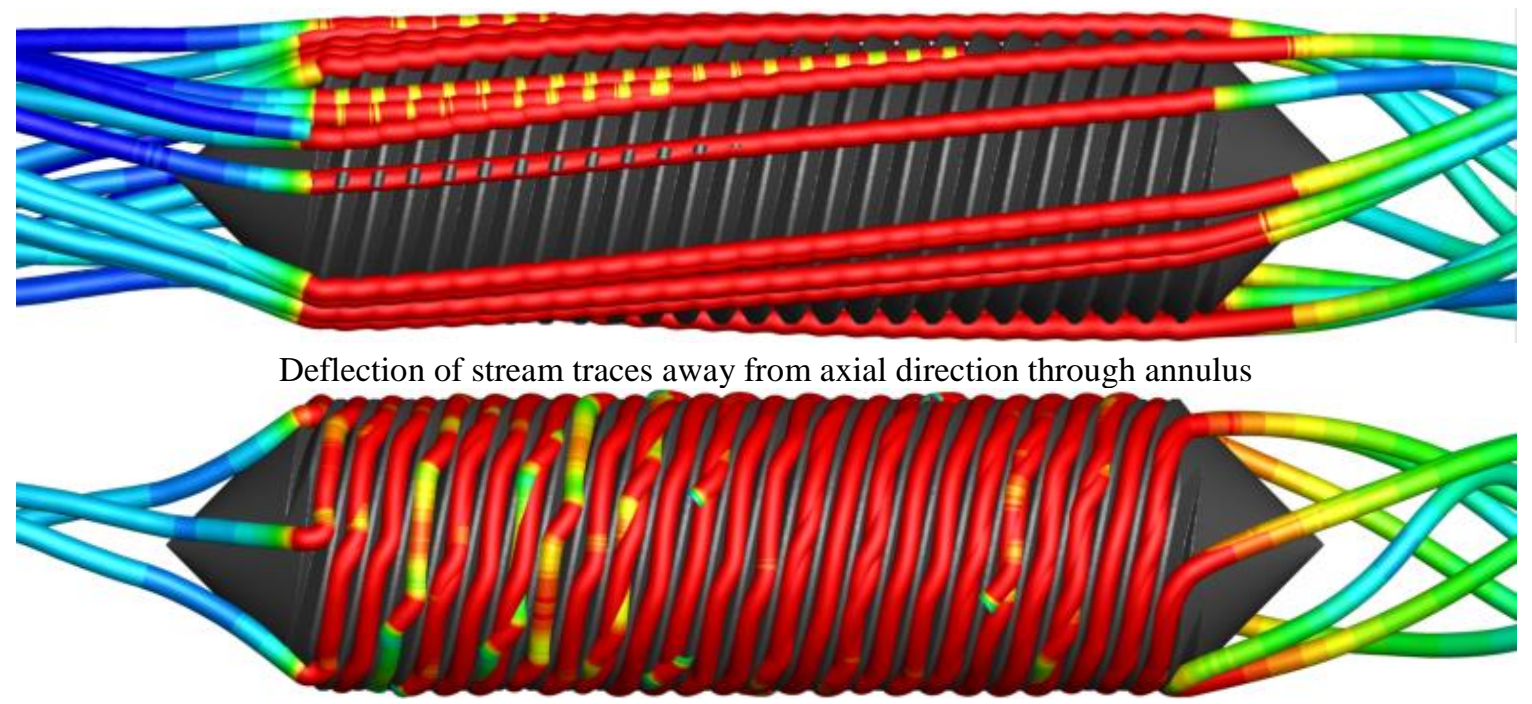

Stream traces flowing through the threaded channels

(a) 


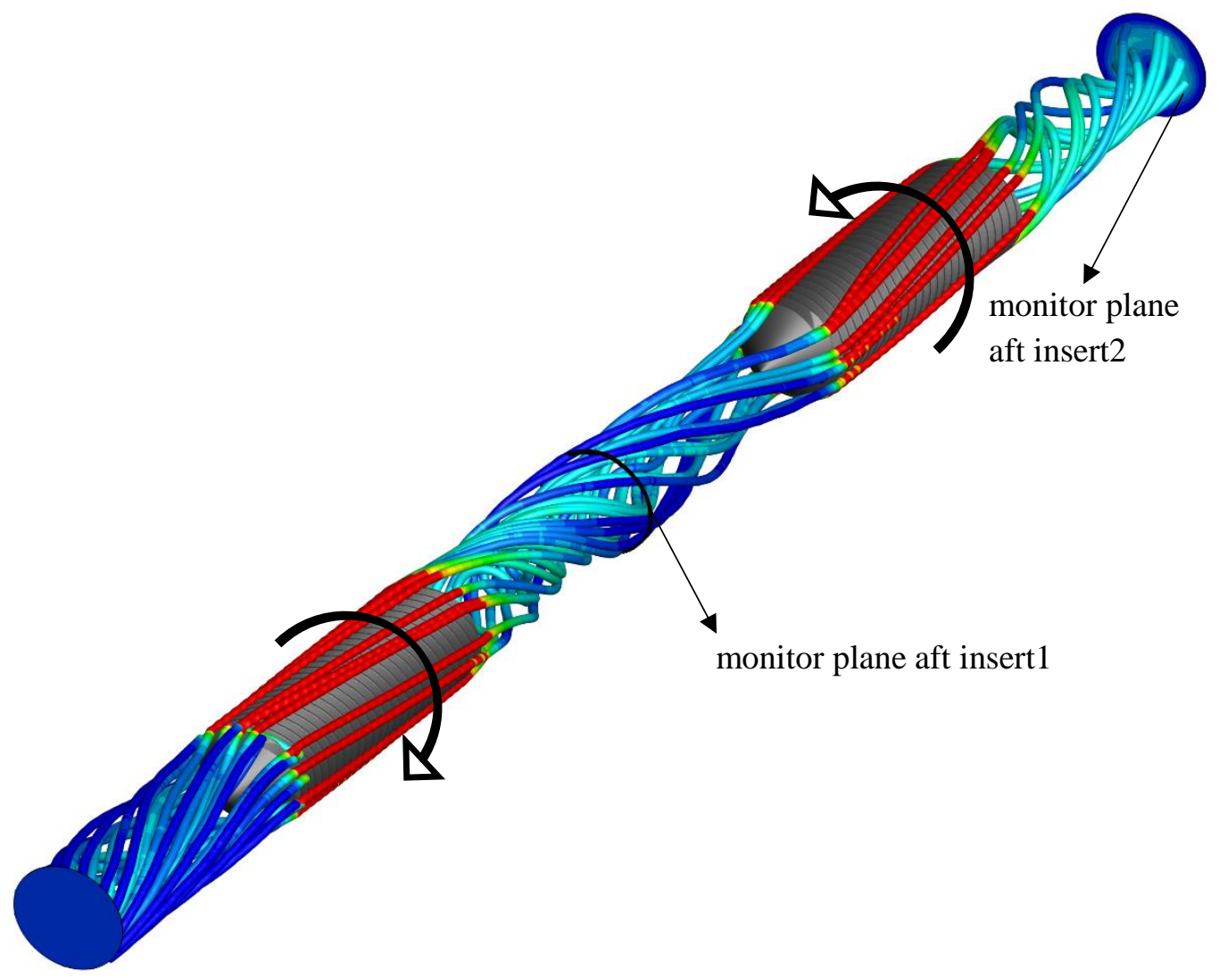

(b)

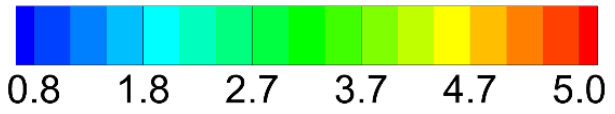

Figure 3: Stream traces coloured by non - dimensional velocity magnitude using inlet velocity over 5channel inserts at $R e=400$. (a) Cross-flow effect between the stream traces; (b) Switching of flow direction aft inserts

A comparison of the non-dimensional cross-flow velocity contours at different $R e$ for 5 -channel design is shown in Figure 5. High magnitude of cross-flow velocity is observed in the annular region and the conecone region, whereas a negligible change in the cross-flow velocity in the extension region between the two distant inserts up to $R e \leq 400$ (Figure 5a). With a further increment in $R e$, i.e., above $R e \geq 800$, few pockets of non-uniform velocity variation are observed in the extension region, indicating the destruction of the smooth swirling effect. Similar flow phenomena are observed from the axial cut planes at the outlet surface (Figure 5b) where the symmetry of the velocity field gets lost with an increase in $R e$ (for 1600). 7-channel and 9-channel designs too, exhibit an analogous flow behavior as exhibited by 5-channel design. 


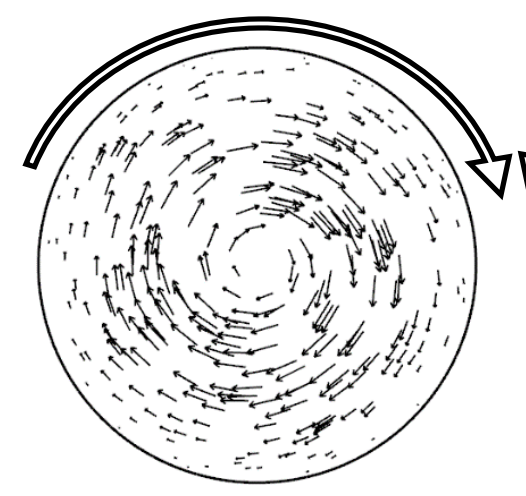

(a)

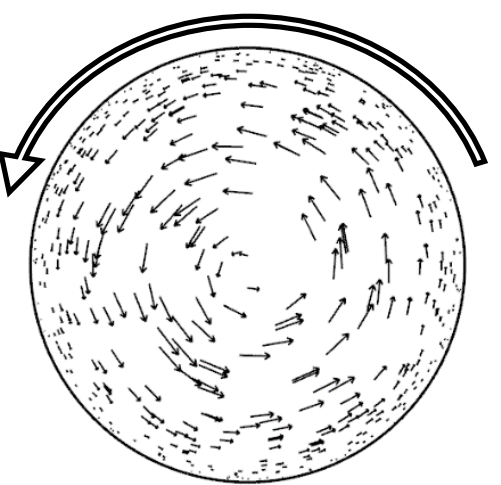

(b)

Figure 4: Velocity vectors drawn on the cut planes aft of each insert indicating the switching of flow direction and swirling effect over 5 - channel inserts at $R e=400$. (a) Plane aft of insert1;

(b) Plane aft of insert2

(maximum length of the vector indicates magnitude $u / u_{\text {inlet }}=2$ )

Quantitative comparison of different channel designs in terms of pressure drop $(\mathrm{Pa} / \mathrm{m})$, frictional factor $(f)$, and Poiseuille number ( $f R e$ ) variation with Reynolds number (Equation 6-7) are shown in Figure 6. Published results for other designs of passive mixers are also included for the sake of comparison. The geometric details of the inserts (both smooth and threaded) have been discussed in Table 2 and Figure 2 respectively. As discussed in Table 2, the mean diameter of the smooth surface insert is $23.68 \mathrm{~mm}$, and the total diameter of the pipe is $25.4 \mathrm{~mm}$. For threaded inserts having the same diameter, as the numbers of channels are increased, the deviation of the flow from the axial direction decreases (deviation observed in the stream traces contour in Figure 3a), thereby resulting in less energy loss. Therefore, at any given $R e$, Poiseuille number and pressure drop are least for the case having the highest number of channels (inner plot in Figure 6a and Figure 6b-c), with un-threaded insert or smooth surface insert exhibiting the least magnitude (no threading/smooth surface $=>$ infinite channels). Screw passive mixer design exhibits a higher magnitude of both pressure drop and Poiseuille number compared to other devices cited from literature..$^{25,33-}$ 35,44,55,56,70 Each of the classes of the configurations (both smooth and threaded inserts) discussed in Table 1 not only enhances mixing but also results in an increment in pressure drop. Since the passive mixer design consisting of the threaded insert have all the characteristics of the classes defined in Table 1 (i.e., by using bends: due to channels formed by threading, varying cross-sectional area, using inserts which allows splitrecombine of flow streams), higher pressure drop or Po are realized. One way to reduce the energy dissipation is to modify the clearance between the insert and the pipe. As seen in the pressure drop plot (Figure 6a), an increase in the pipe diameter from $25.4 \mathrm{~mm}$ to $26 \mathrm{~mm}$ results in a significant reduction of the pressure losses by around $45.2 \%$. A small increment in the outer diameter of the pipe creates a substantial gap between the outer diameter of the insert and the inner diameter of the pipe. For the case of 
larger diameter pipe, fluid intends to follow the least resistance path, i.e., through the clearance, thereby reducing the cross-flow effects (as discussed for Figure 3a). This causes less deviation of the flow from the axial direction and may reduce mixing/heat transfer. Therefore, the clearance between the insert and the pipe forms one of the major parameters for optimizing the flow through the annulus region and the threading/channels (Figure 3a). Though the energy dissipation is observed to be higher for this design, there are many advantages and will be discussed in the later section. 


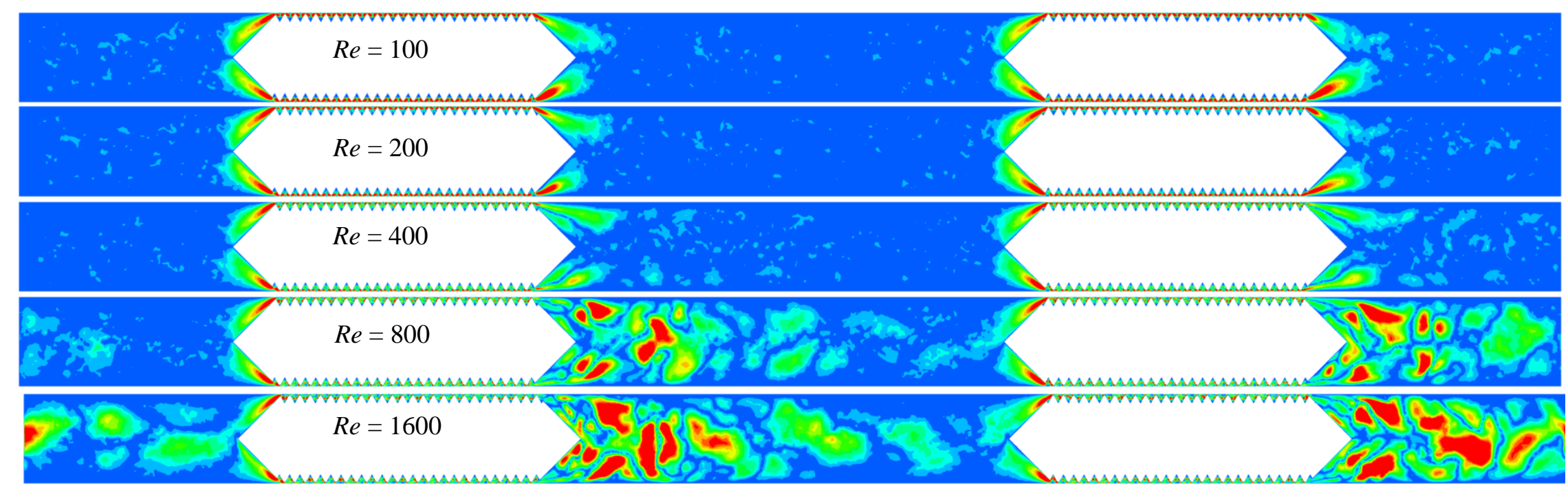

(a)

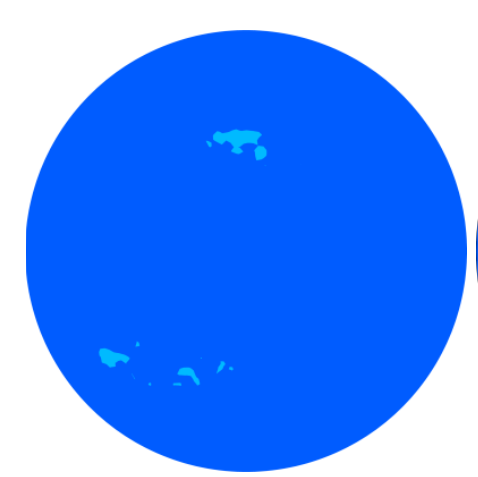

$\operatorname{Re}=100$

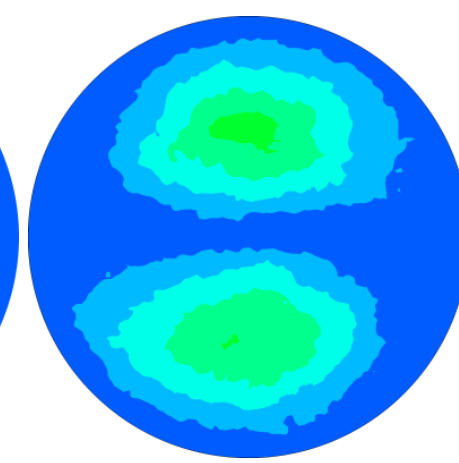

$\operatorname{Re}=200$

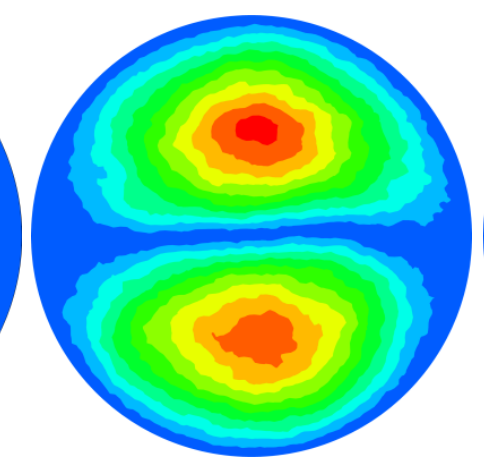

$R e=400$

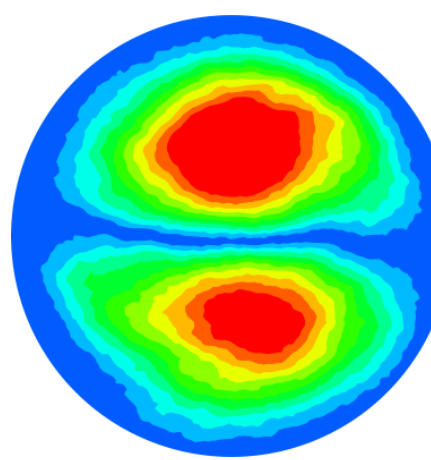

$\operatorname{Re}=800$

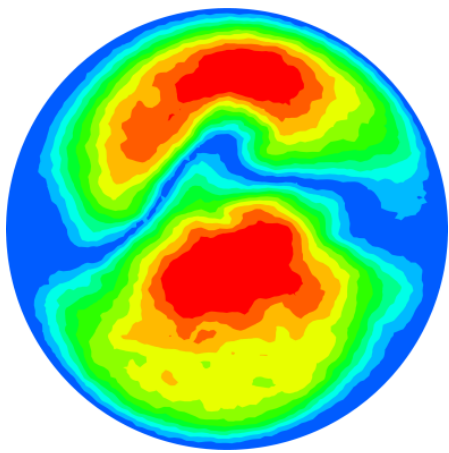

$\operatorname{Re}=1600$

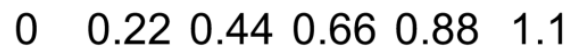

(b)

Figure 5: Non-dimensional cross-flow velocity contours for 5-channel design at different $R e$. (a) plane along the axis (b) outlet plane (inlet velocity was used for normalizing the cross-flow velocity) 


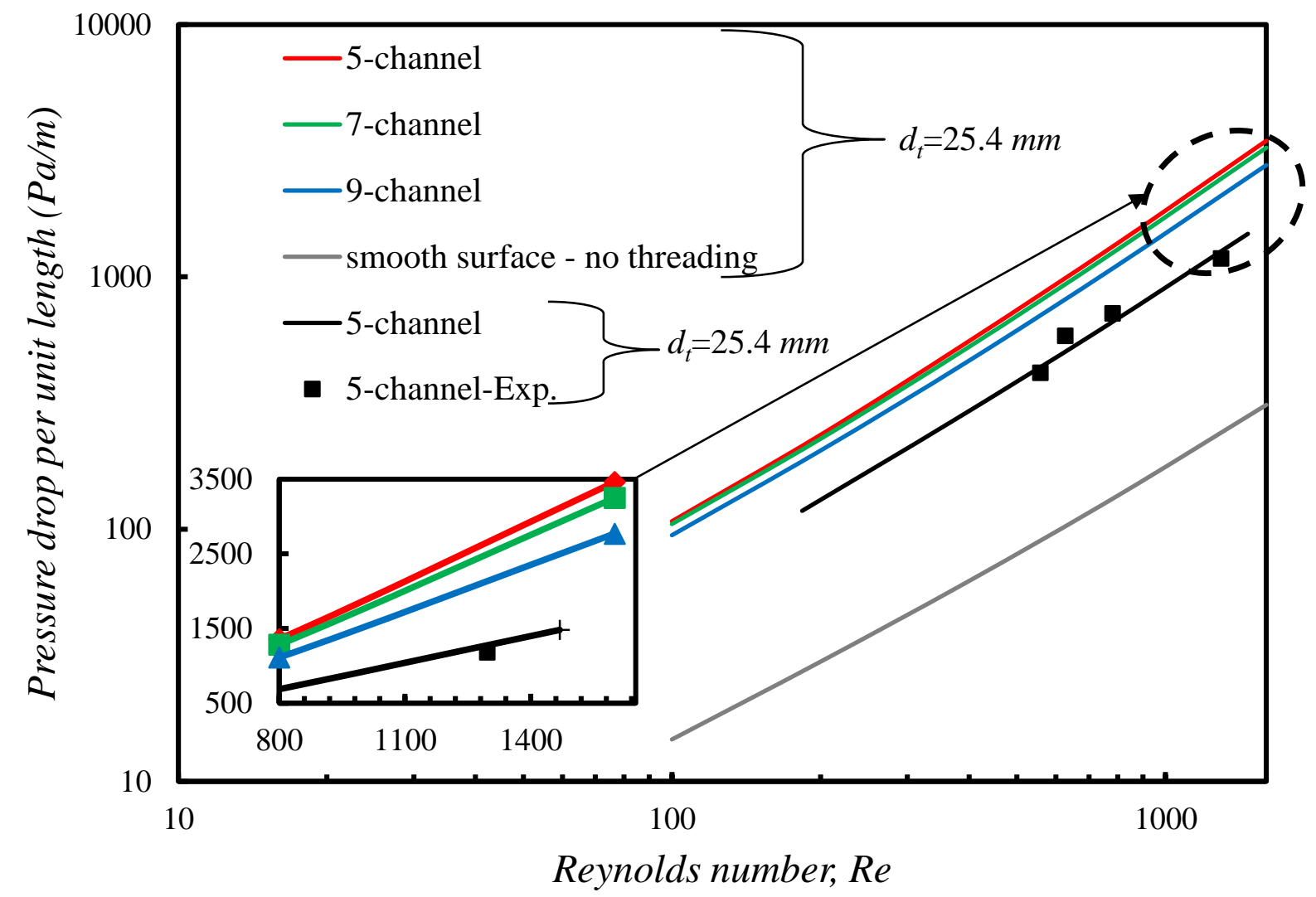

(a)

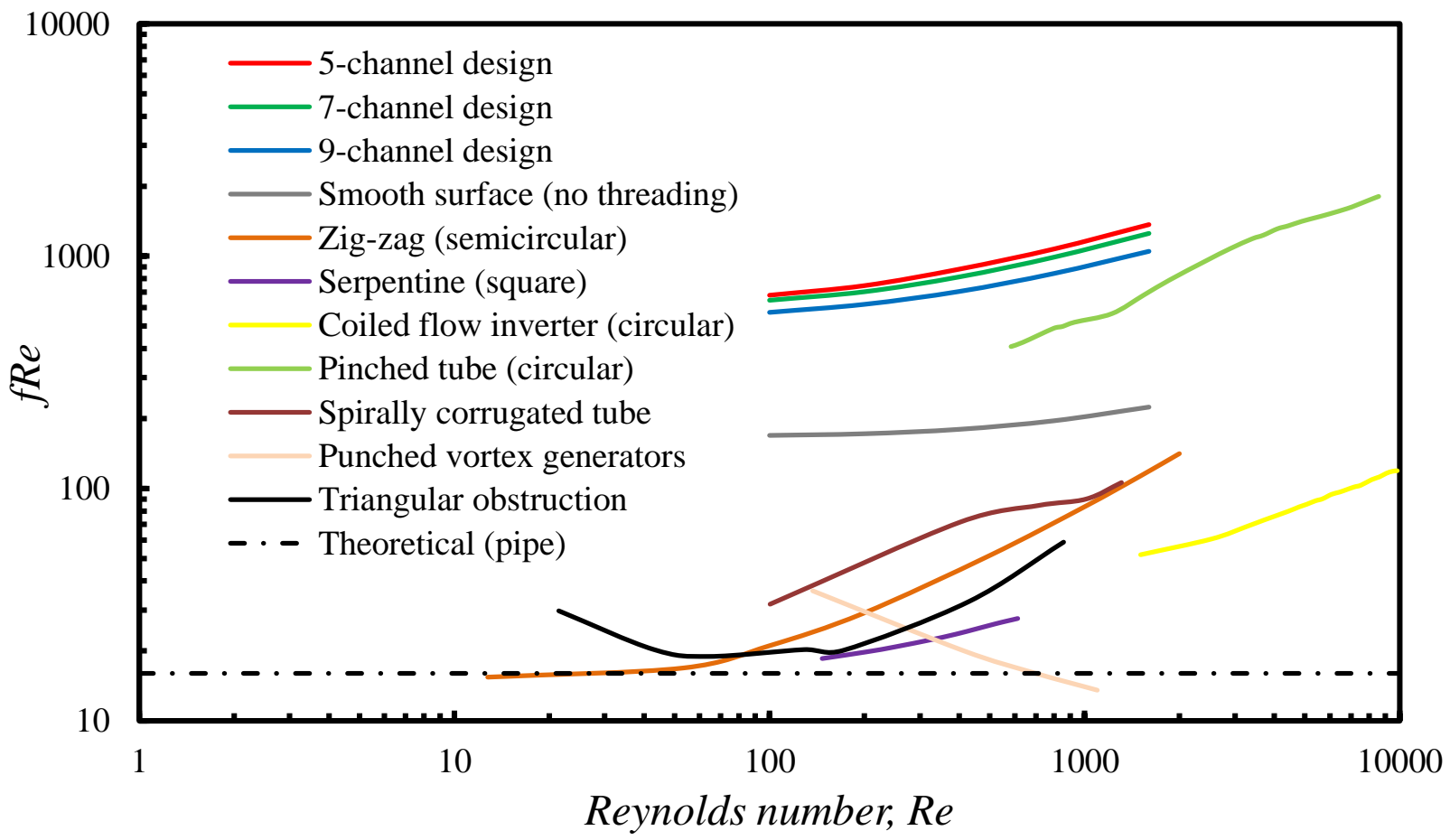

(b) 


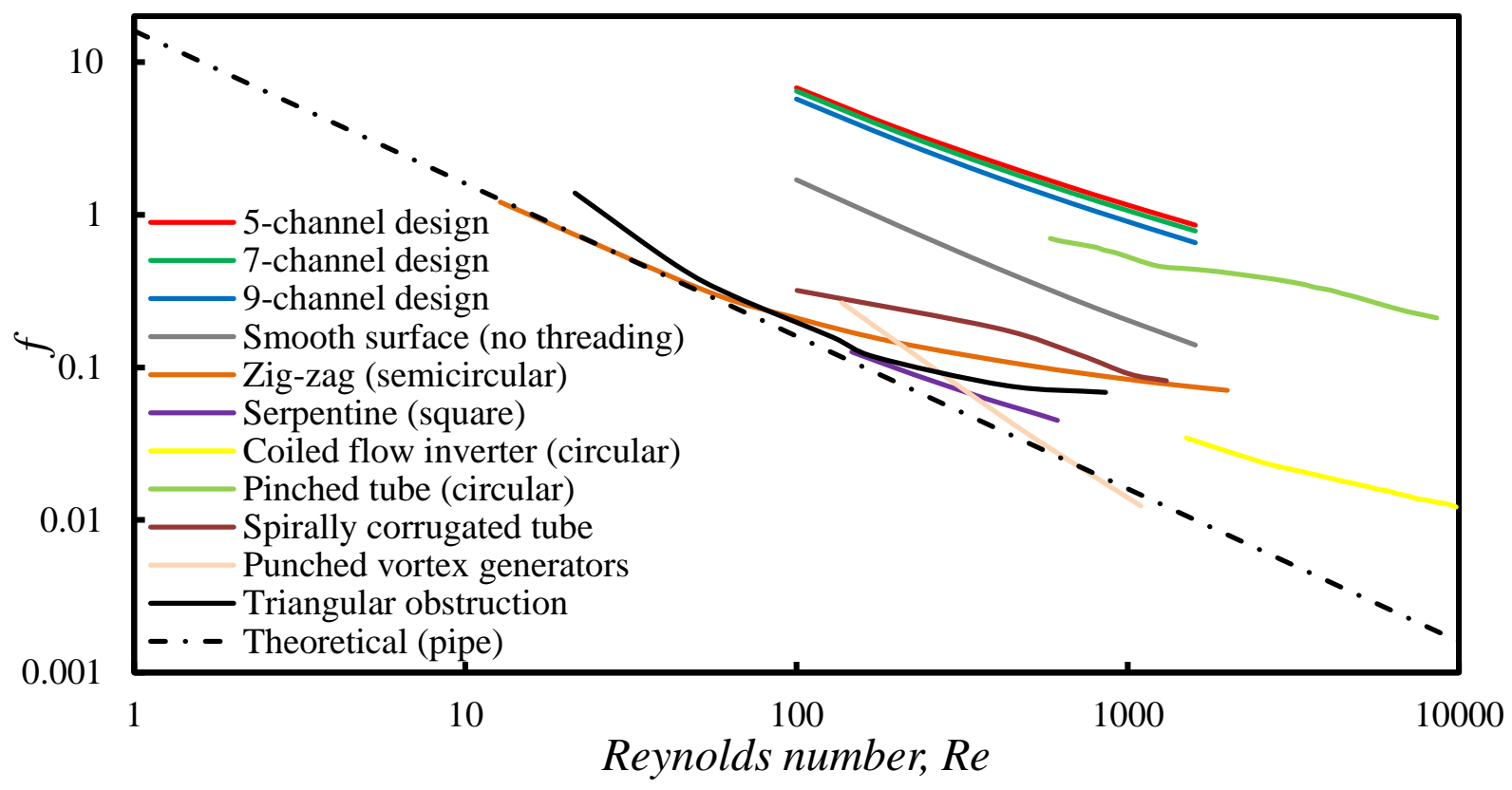

(c)

Figure 6: Variation in flow parameters with $R e$ for different studied designs and literature. (a) Pressure drop per unit length, $d P / L(P a / m)$, where $L$ is the total length of the considered domain consisting of two threaded inserts; (b) Poiseuille number, $f R e$; (c) frictional factor, $f$.

5-channel design — Present study, 7-channel design — Present study, 9-channel design — Present study, smooth surface (no threading) - Present study; Zig-Zag (semicircular) - Yoon et al. ${ }^{33}$; Serpentine (square) - Karale et al. ${ }^{34}$; Coiled flow Inverter (circular) - Kumar et al. ${ }^{35}$; Pinched tube (circular) Hasabnis et al. ${ }^{25}$; Spirally corrugated tube - Kareem et al. ${ }^{44}$; Punched vortex generator - Zhang et al.

${ }^{55}$; Triangular obstruction - Khalde et al. ${ }^{56}$; Theoretical (pipe) $-\cdot-$ Shah and London ${ }^{70}$

\subsection{Heat transfer}

Heat transfer enhancement is one of the primary concerns in a variety of applications, may it be for carrying out an exothermic/endothermic reaction, or as a heat exchanger. ${ }^{71}$ Number of passive heat transfer enhancement techniques has been developed with different insert designs which enhance convective heat transfer due to the generation of swirling effect or diffusion. ${ }^{72}$ Heat transfer enhancement has successfully been demonstrated due to swirl, but the problem of dead zones has not yet been completely overcome for compact designs. ${ }^{43,44}$ The proposed threaded design does not exhibit any dead zones and thereby can ensure a minimum spatial variation of temperature (on a plane normal to the axis of the mixer) as is observed within the dead zones. A detailed computational study has been carried out over different designs of inserts for evaluating their heat transfer capabilities and has been compared with straight pipe and unthreaded inserts. As discussed previously, model verification for heat transfer has been done using a straight pipe, which is in agreement with the theoretical and experimental studies. 
The non-dimensional spatial variation of temperature indicating the thermal mixing has been shown in Figure $7 \mathrm{a}$ for 5-channel configuration at different selected $R e$. No significant variations in temperature exist in the radial direction to the generated swirling flow, whereas a smooth increment in the temperature is observed in the axial direction. Higher velocity and velocity gradients developed near the pipe walls due to the swirling flow ensures enhanced advection of heat from the walls to the fluid present in the core, thereby maintaining reduced spatial variation in the radial direction. The same can be inferred from the temperature contours generated over the outlet plane of the configuration (Figure $7 \mathrm{~b}$ ) at different $R e$. In the case of smooth surface inserts (no threading), significant variations in temperature are observed due to the absence of a swirling component and have been shown on the generated axial (Figure 7a) and outlet planes (Figure 7b) for $R e=800$.

A quantitative comparison of heat transfer for different designs of passive mixers is shown in Figure 8. $\mathrm{Nu}$ has been normalized using theoretical values of straight pipe..$^{70}$ The threaded design is observed to perform better than other selected literature designs. Increasing number of channels force the fluid parcels to follow a shorter path from inlet to outlet. Therefore, fluid wall contact time increases with a decrease in the number of channels, thereby improving the heat transfer. Hence, increasing the number of channels results in the reduction of normalized $\mathrm{Nu}$, with minimum $\mathrm{Nu}$ observed for the case of smooth surface design, i.e., virtual infinite channels (Figure 8a). Threaded inserts are found to be capable of achieving higher heat transfer when compared to other passive mixers by several folds. ${ }^{25,33-35,44,55,56,70}$

Heat transfer enhancement ratio $(\eta)$, which relates heat transfer and momentum transfer were used to compare the studied configurations and with the literature (Equation 14). The objective functions and constraints used for defining $(\eta)$ and its significance has been discussed previously in section 3.4. $N u_{\text {pipe }}$ and $f_{\text {pipe }}$ are theoretical values for the straight pipe without any inserts. ${ }^{70}$ It is observed that significant enhancement in the heat transfer is achieved by using inserts compared to other conventional designs (Figure $8 \mathrm{~b}$ ). ${ }^{25,33-35,44,55,56,70}$ No significant variation is observed for the different selected threaded designs, except for the inserts without any threading (infinite channels) which exhibits the best performance. All the insert designs have been found to perform better than the straight pipe design with reference to the heat transfer enhancement ratio. The enhancement is observed to be seven times higher than the straight pipe design at $R e=1600$. 


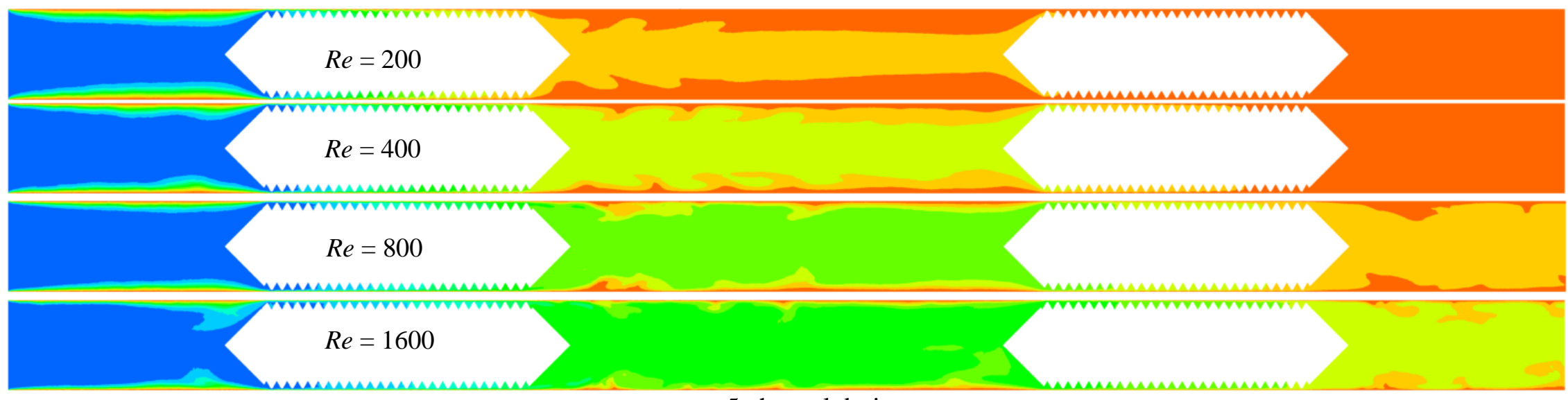

5-channel design

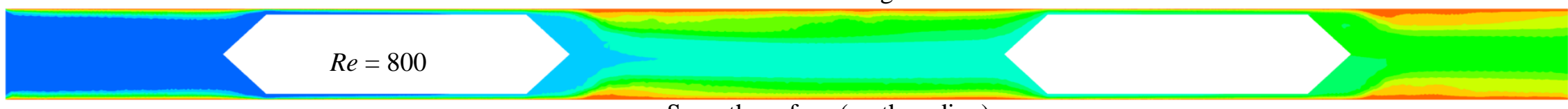

Smooth surface (no threading)

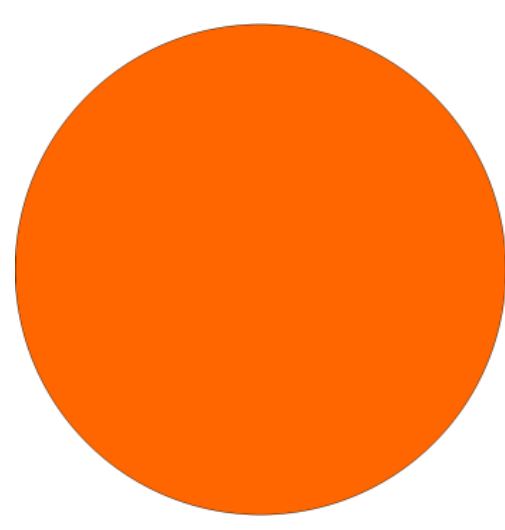

$\operatorname{Re}=400$ (a)

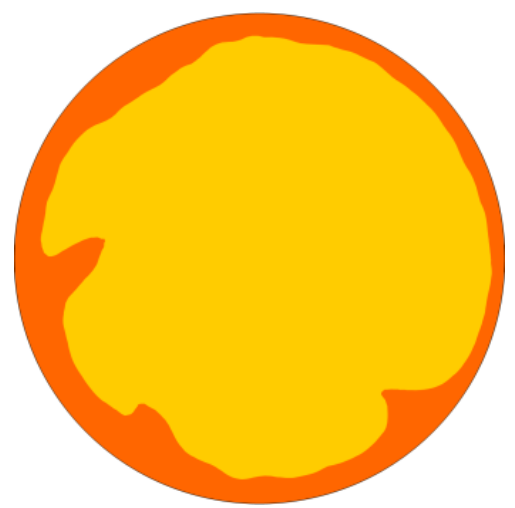

$\operatorname{Re}=800$

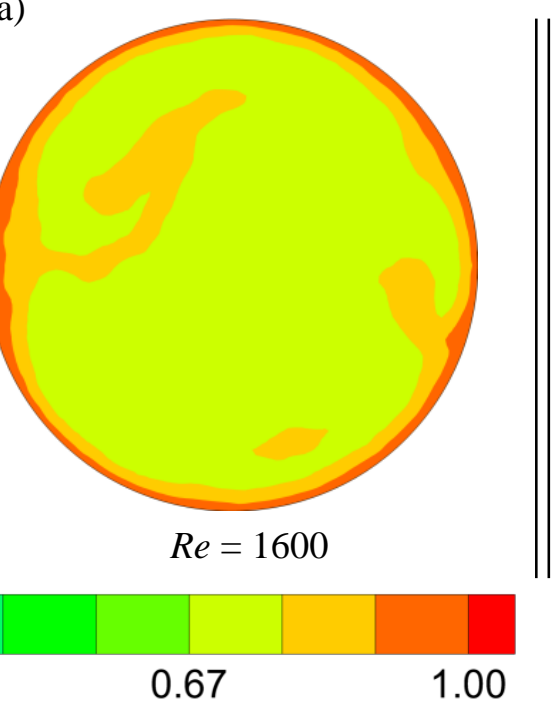

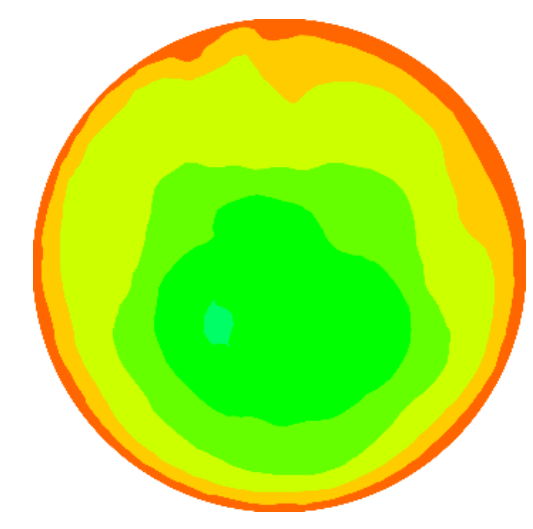

$\operatorname{Re}=800$

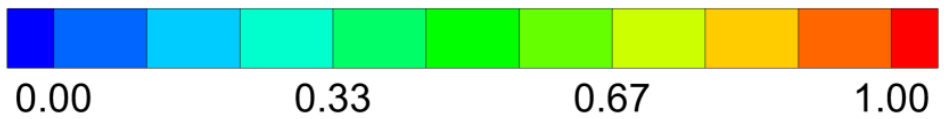

(b)

Figure 7: Dimensionless temperature contours for 5-channel and smooth surface design at different $R e$. (a) plane along the axis (b) outlet plane 


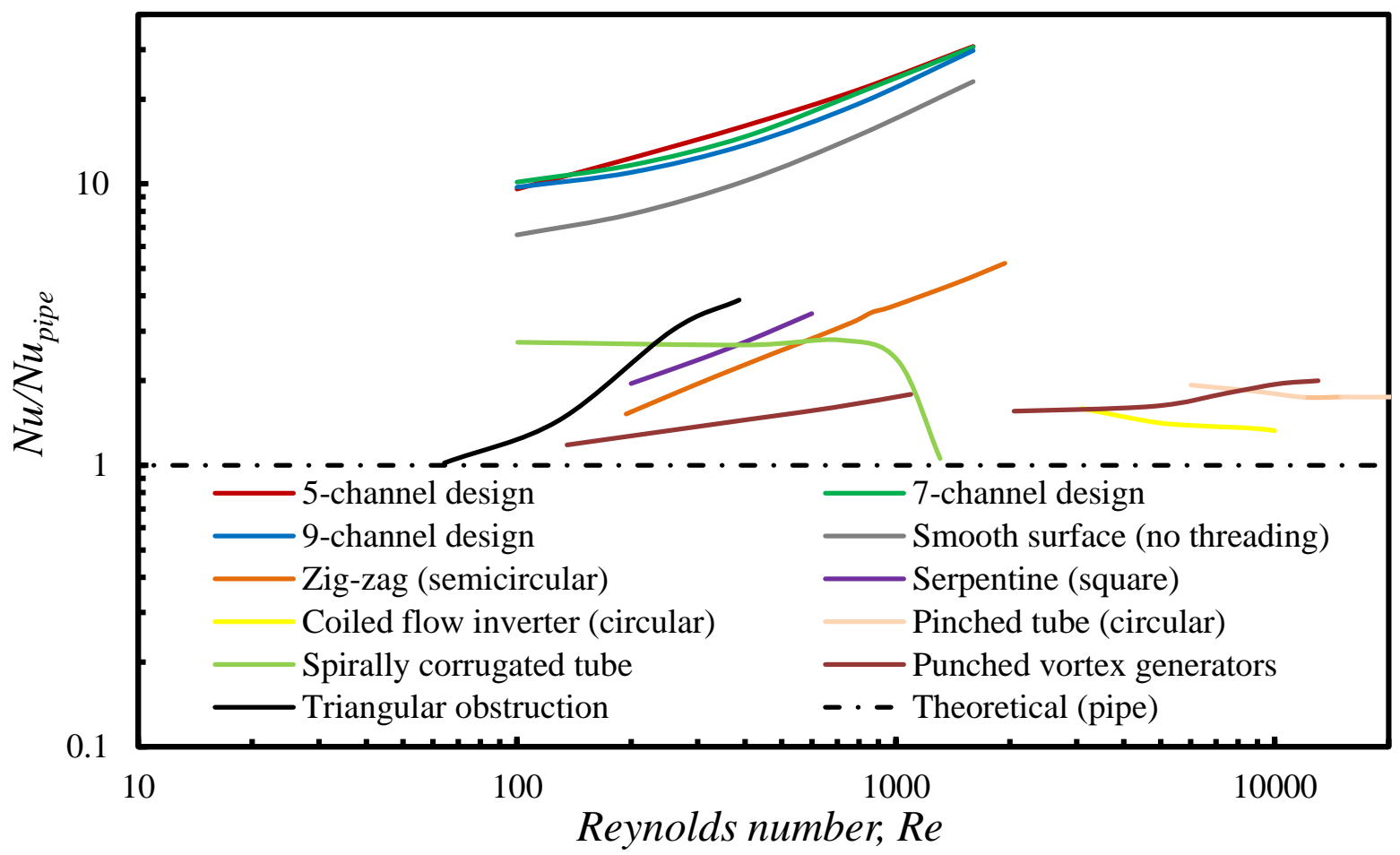

(a)

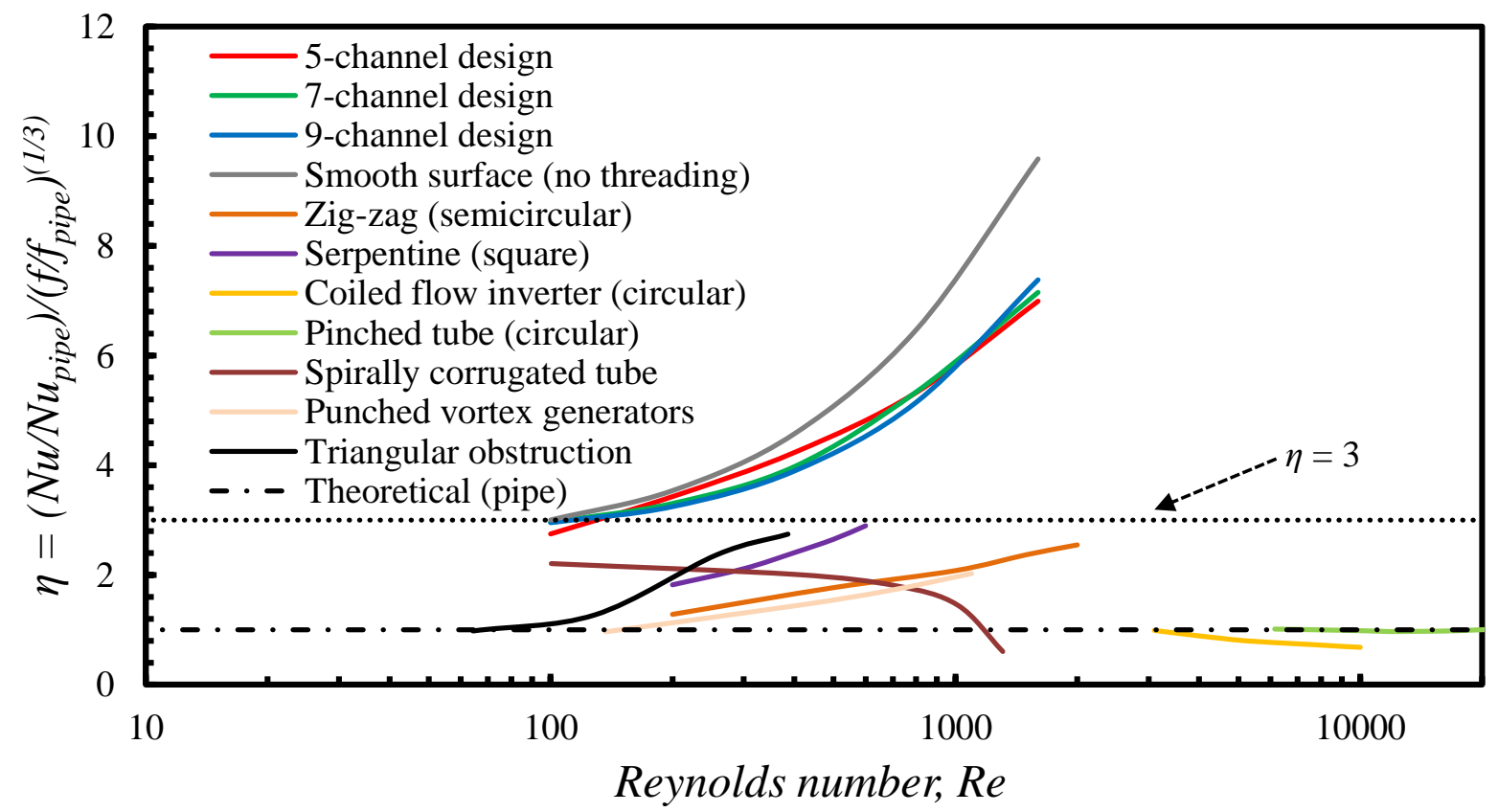

(b)

Figure 8: Variation of heat transfer parameters with $R e$ for different studied designs and literature.

(a) Nusselt number normalized using straight pipe (b) Heat transfer enhancement ratio ( $\eta$ ).

5-channel design - Present study, 7-channel design — Present study, 9-channel design — Present study, Smooth surface (no threading) - Present study; Zig-Zag (semicircular) - Yoon et al. ${ }^{33}$; Serpentine (square) - Karale et al. ${ }^{34}$; Coiled flow Inverter (circular) - Kumar et al. ${ }^{35}$; Pinched tube (circular) - 
Hasabnis et al. ${ }^{25}$; Spirally corrugated tube - Kareem et al. ${ }^{44}$; Punched vortex generator - Zhang et al. ${ }^{55}$; Triangular obstruction - Khalde et al. ${ }^{56}$; Theoretical (pipe) - - - Shah and London ${ }^{70}$

\subsection{Mixing}

Reliable characterization of mixing is crucial for an accurate prediction and designs of the reactors. A variety of methodologies have been developed by employing tracers to arrive at the mixing index or mixing intensity using experiment, analytical and computational tools. ${ }^{73}$ Here, we have simulated the proposed design of the passive mixer using the multispecies model. The boundary conditions and methodology has been explained previously in Section 3.2. Figure 9 indicates the path lines (colored using the mass fraction of the fluid) developed within the 5-channel design for understanding the spatial behavior of mixer/reactor. Mass fraction equal to 0 or 1 indicated no mixing, whereas 0.5 indicts a perfectly mixed fluid. Each halves of the inlet plane have blue or red color indicating zero mixing, whereas the outlet plane indicates mixed fluid (having mass fraction MF between $0<\mathrm{MF}<1$ ). The pathlines colored by mass fraction indicates a change in the color from blue/red $(\mathrm{MF}=0 / 1)$ to green $(\mathrm{MF}=0.5)$ as it proceeds from the inlet towards the outlet for threaded inserts indicating improvement in mixing.

At low $\operatorname{Re}(\operatorname{Re} \leq 100)$, the deflection of pathlines in the threading direction is observed in the annulus region (between insert and pipe), whereas pathlines more or less travel in a straight path in the section between the two inserts of opposite threading. The pinching effect due to the cone-cone design and the shear generated due to the threaded inserts in the annulus region are the primary sources of mixing for low Re. Patches of MF of magnitudes 0.7 and 0.4 are observed on the outlet plane contour, indicating that the fluid is not perfectly mixed. With an increase in $R e$, the inertia of the flowing fluid also increases, thereby retaining the swirl even aft of the inserts. Therefore, for $R e \geq 200$, the pathlines are observed to be swirling in the threading direction in the whole of the domain (i.e., in both annulus and mixing region between the two inserts). MF on the outlet plane is observed to improve with an increase in the $R e$, i.e., its magnitude approaching value of 0.5. As discussed in Section 4.1, destruction of the smooth swirls was observed in the cross-flow velocity contours for $R e \geq 800$ which can also be corroborated by random behavior of the pathlines downstream of inserts. Any further increment in swirl is not possible with the increase in $R e$ and may also result in a decrease in mixing efficiency if operated above these $R e$. Such behavior of pathlines is observed only in the extension region of the mixer, whereas smooth deflection of the pathlines in the threading direction is realized within the annulus region. Similar qualitative behavior of the pathlines and MF variation is observed for 7 and 9-channel design and has been shown in Figure S8 of the SI for reference. 


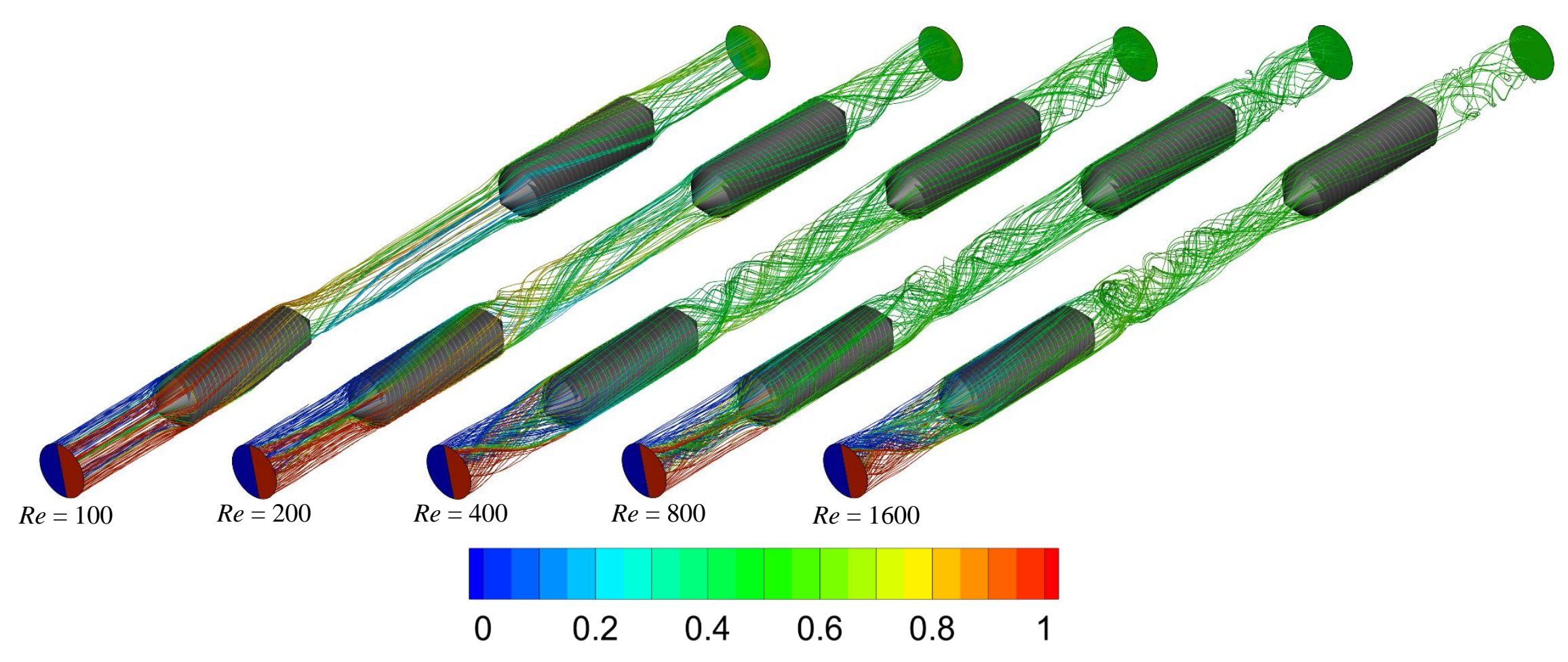

Figure 9: Pathlines exhibiting the tracer mass fraction for 5-channel design at different $R e$ 
The variation of $I_{M}$ along the length of the mixer for the studied insert designs is shown in Figure 10, and $I_{M}$ variation with $R e$ at the outlet of the mixer/reactor is shown in Figure 11. Figure 11a indicates the three configurations of different threaded channels, i.e., 5-channel, 7-channel and 9-channel design. Figure 11b is shown to compare the performance of the threaded inserts with the literature. As discussed earlier, the axially flowing stream traces can be segregated into two classes: ones following the $\theta$ direction within the annulus, whereas the other ones following the insert channels. Stout shearing is induced due to this flow phenomena resulting in enhanced mixing in the annulus region formed by the inserts and the pipe. Mixing in the extension region between the two inserts also takes place due to the generated swirl aft of the inserts. Therefore, the mixing intensity, $I_{M}$ (Equation 15) is found to be increasing in the axial direction for the whole of the mixer/reactor (Figure 10). There exist a sudden rise/fall in certain regions which is mainly due to the secondary vortices formed aft of the inserts. Modifications in the design were done to avoid the wake region and have been discussed in the later section. The rate of increment of $I_{M}$ is higher in the annulus region due to the pinching effect caused by the nose of the insert and shearing due to the segregated stream traces. With an increase in $R e$ from 100 to $800, I_{M}$ is observed to be increasing at any section drawn normal to the axis as the swirling strength increases with $R e$ (Figure 10). With further increment in $R e$ i.e., for $R e$ $=1600, I_{M}$ is found to be less than that arrived for $R e=800$. This indicates an inverted dome behavior with a maximum of the dome lying between $R e$ of 800 and 1600 (Figure 10 and Figure 11a). Similar behavior has been found for 5-channel design (Figure S9a of SI). For 9-channel design, the $I_{M}$ was higher for $R e=$ 1600 compared to $R e=800$, indicating that the decrement in the $I_{M}$ after achieving its maximum value with $R e$, gets delayed as the number of channels are increased (Figure 11a and Figure S9b of SI). The angle made by the threaded channel to the axis of the mixer decreases with increase in the number of channels (Table 2). Fluid in such a scenario is forced to smaller deflection for higher number of channels with zero deflection for infinite channels (smooth surface design). Therefore, for a unit of two inserts having opposite threading, the critical $R e$ above which $I_{M}$ starts decreasing after reaching the maximum value increases with an increase in the number of channels.

Generally, a passive mixer design is expected to deliver $I_{M}$ above $90 \%$ as per the standards. ${ }^{5}$ From Figure $11 \mathrm{~b}$, we observe that several passive mixer designs qualify this requirement at a different range of $R e$. The threaded screw inserts design has a wider range of $R e$ (100-1600), maintaining $I_{M}$ above $90 \%$ as compared to most of the selected devices from literature.

To exhibit the importance of threading over the insert surface, smooth surface (no threading) inserts that do not generate any swirling effects have been simulated for $R e=400$. Unlike threaded inserts, no substantial increment in $I_{M}$, in the annulus region is observed for smooth surface (no threading) inserts, except near insert nose region due to the pinching effect (Figure 10). There is a positive slope for $I_{M}$ in the annulus 
region and the extensional region, primarily due to the diffusion. We have also simulated mixing intensity variation for straight pipe without inserts at $R e=400$ and observe $I_{M}$ value around $2.6 \%$ at the exit of the pipe.

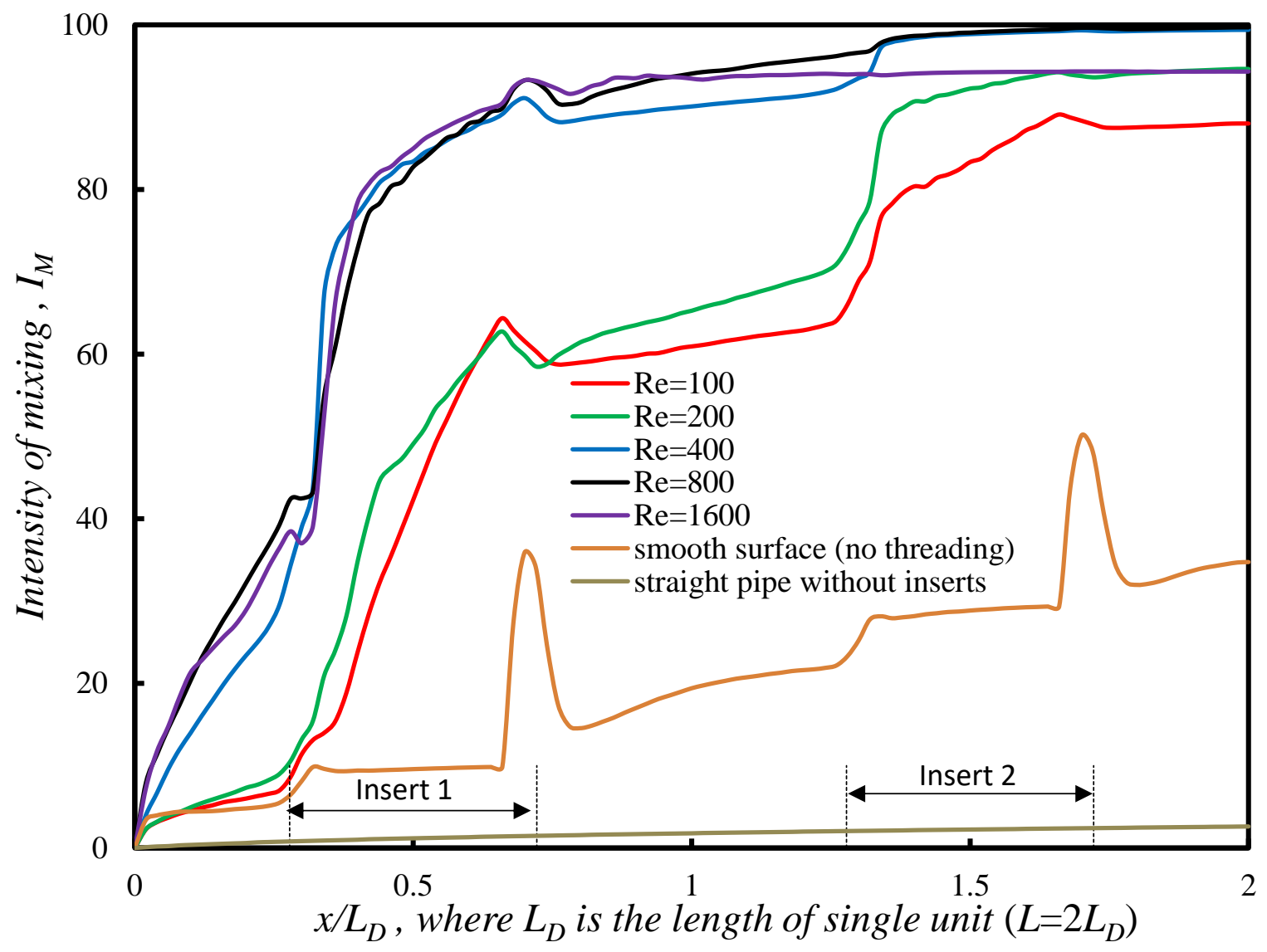

Figure 10: Mixing intensity $\left(I_{M}\right)$ variation along the length for 7-channel design consisting of two inserts with $R e . I_{M}$ variation for smooth surface (no threading) and straight pipe without inserts shown for exhibiting the effect of threading and obstruction. 


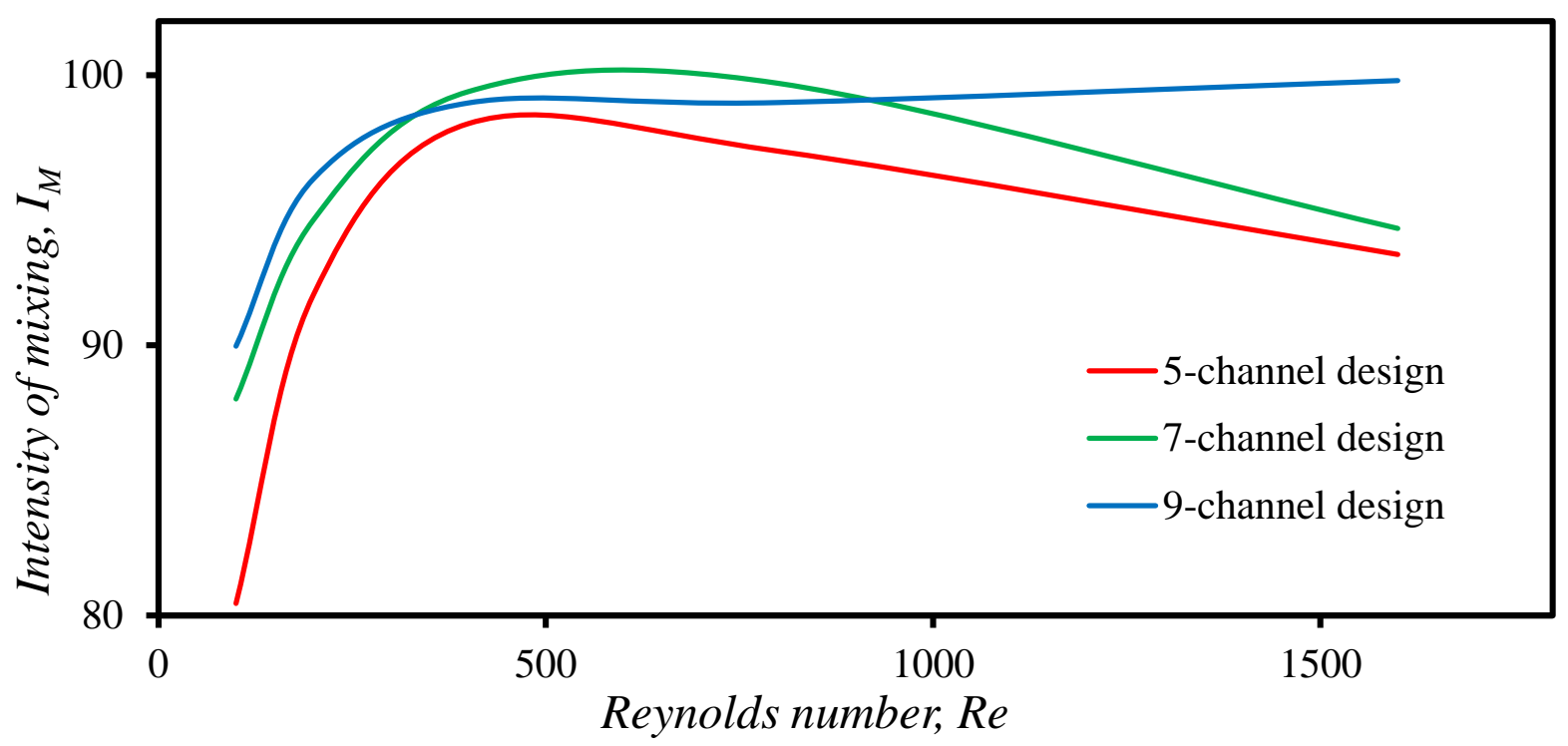

(a)

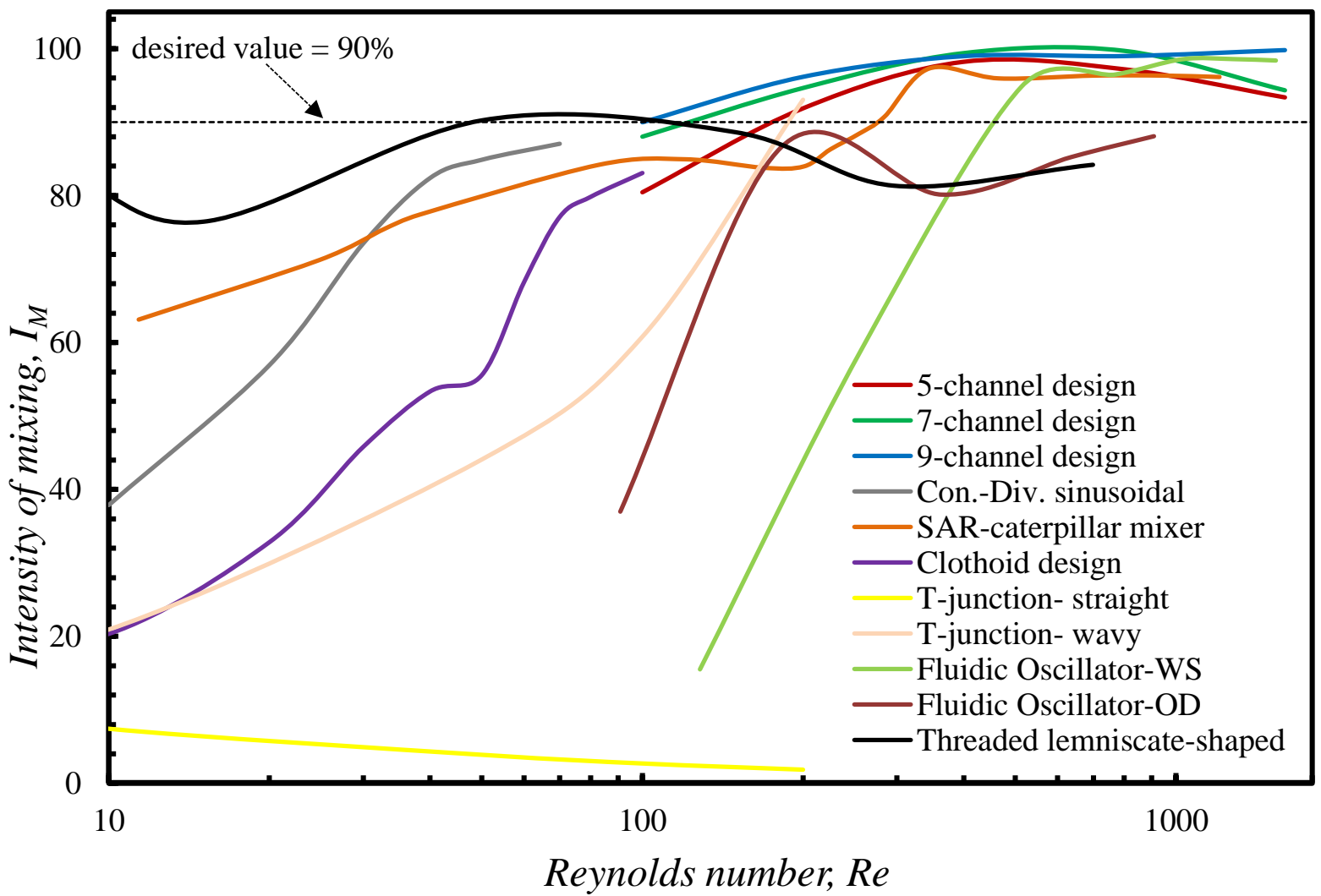

(b)

Figure 11: Variation of mixing intensity with Reynolds number, Re. (a) Comparison of studied designs (b) Comparison of studied designs with literature.

5-channel design — Present study, 7-channel design — Present study, 9-channel design — Present study, Convergent-divergent sinusoidal walls - Afzal and Kim ${ }^{26}$; SAR-caterpillar mixer - Hermann et al. ${ }^{49}$; Clothoid design - Pennella et al. ${ }^{23}$; T-junction-straight - Solehati et al. ${ }^{74}$; T-junction-wavy - Solehati et al. ${ }^{74}$; Fluidic Oscillator-WS - Khalde et al. ${ }^{75}$; Fluidic Oscillator-OD $-\mathrm{Xie}$ and $\mathrm{Xu}^{75,76}$; Threaded lemniscate-shaped - Rafeie et al. ${ }^{42}$ 


\subsection{Overcoming wake region or secondary vortices formation aft inserts}

The presence of dead zones or secondary vortices within the reactor causes fluid parcels present in that region to remain unmixed or unreacted. High magnitudes of pressure and temperature gradients also exist in the secondary vortices. This may result in a significant loss in the throughput and the quality of the product obtained from the process. The problem of secondary vortices /dead zones/backflow does exist in a number of well-established designs and has been discussed in Table 1. Understanding the negative impact of secondary vortices/dead zones presence within the reactor, a lot of efforts have been put in for geometric optimization. One of the successful attempts has resulted in the development of Advanced Fluid Reactor (AFR) design by Nieves-Remacha et al. 2015.77

As discussed in Section 4.3, the existence of a negative velocity region (wake) is the primary reason for the fall in mixing intensity. Whenever fluid is forced to turn through a sharp curvature, i.e., in the aft region of the insert, the fluid tends to separate from the surface resulting in the formation of secondary vortices past the separation point. The tracer diffuses into the wake region and forms a mixture but gets alienated from the main flow stream resulting in higher mixing intensity values in that region. Therefore, a detailed flow analysis has been done to modify the design such that the secondary vortices/wake may be avoided as done by Remacha et al. 2015. ${ }^{77}$ To visualize and decipher this effect, a simple case of the smooth insert without any threading was also considered (at $R e=400$ ). In order to understand the effect of the negative velocity region, a volume consisting of negative velocities was neglected in the mixing intensity computation and then compared with the original case. Figure 12 shows a comparison of mixing intensity variation along the length of the mixer with and without neglecting the negative velocity region in the computation of mixing intensity. We observe a fall in the increment of mixing intensity aft of the insert if the wake region is not considered into the calculation. The contours of volume fraction and $\mathrm{X}$ velocity have been generated in the region where the rise and fall of mixing intensity due to the wake region are shown in Figure 13. Around $12 \%$ decrease in the mixing intensity is observed when the negative velocity region is neglected (cross-section 6 of Figure 13). From the contours of the adapted region, we observe that the volume which consists of volume fraction near to 0.5 lies in the region of secondary vortices, which cause substantial variation in mixing intensity for the adapted and non-adapted case. A similar wake region is also observed for threaded design, which is mainly due to the higher cone angle of the aft part of the insert.

In order to test the hypothesis of avoiding backflow by using a smaller cone angle, a smooth surface extended end (no threading) case has been simulated at $\mathrm{Re}=400$. Comparison of $\mathrm{X}$ velocity contours and negative $\mathrm{X}$ velocity iso-surface for 5-channel design, smooth surface (no threading) and smooth surfaceextended end (no threading) is shown in Figure 14a. The negative velocity region was found to be extending up to $1.3 \mathrm{~d}$ for 5 -channel design compared to the smooth surface (no threading) design (Figure 14b). With 
a decrease in the angle of the cone from $90^{\circ}$ to $60^{\circ}$, the negative velocity region gets eliminated for smooth surface design (Figure 14b). An interesting point to note that asymmetric flow is developed for smooth surface (no threading) due to the Coanda effect, whereas for the extended end case, the flow is perfectly symmetric (Figure 13 and Figure 14a). 


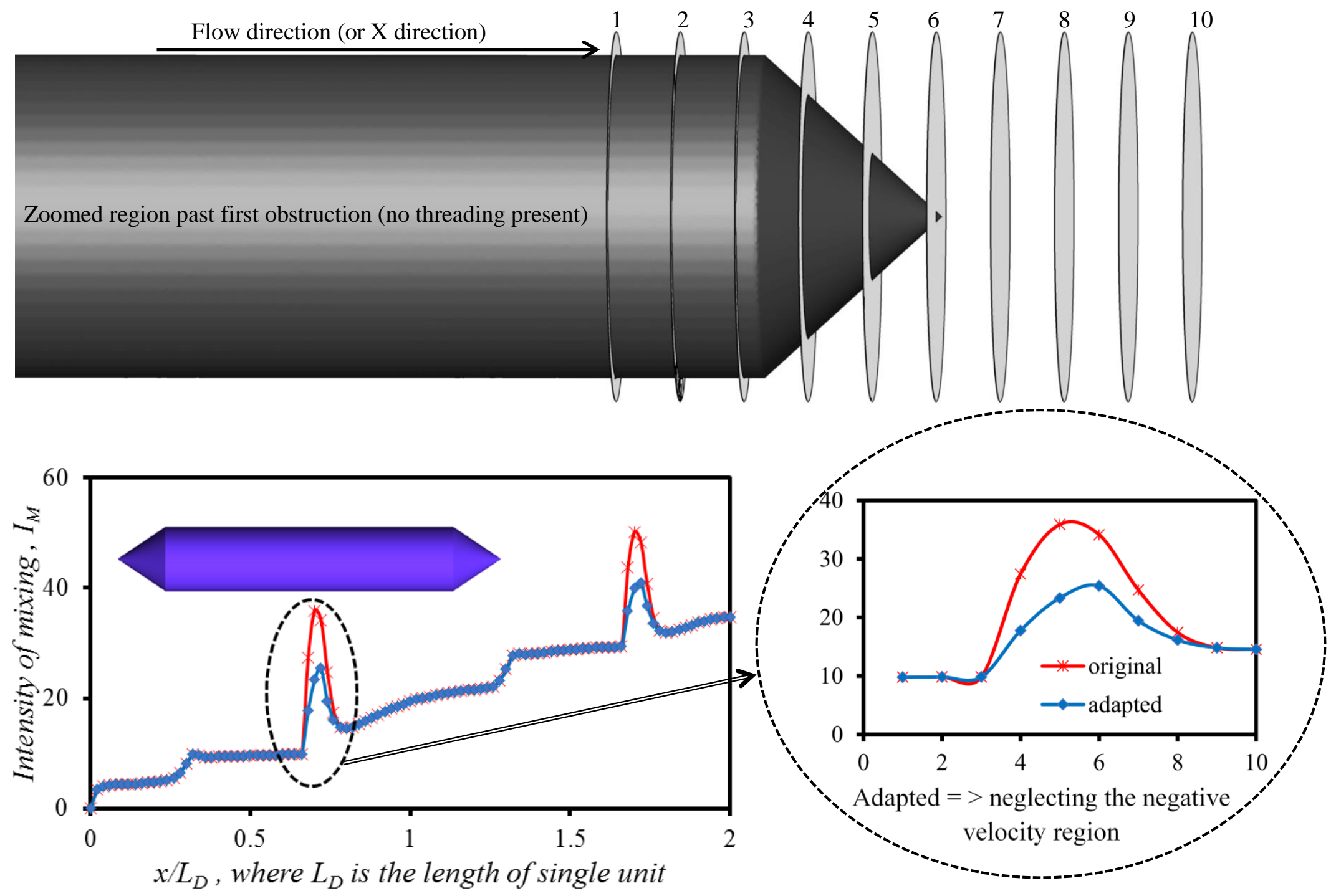

Figure 12: Comparison of mixing intensity variation along the length of the mixer with and without neglecting the negative velocity region in the computation of mixing intensity 

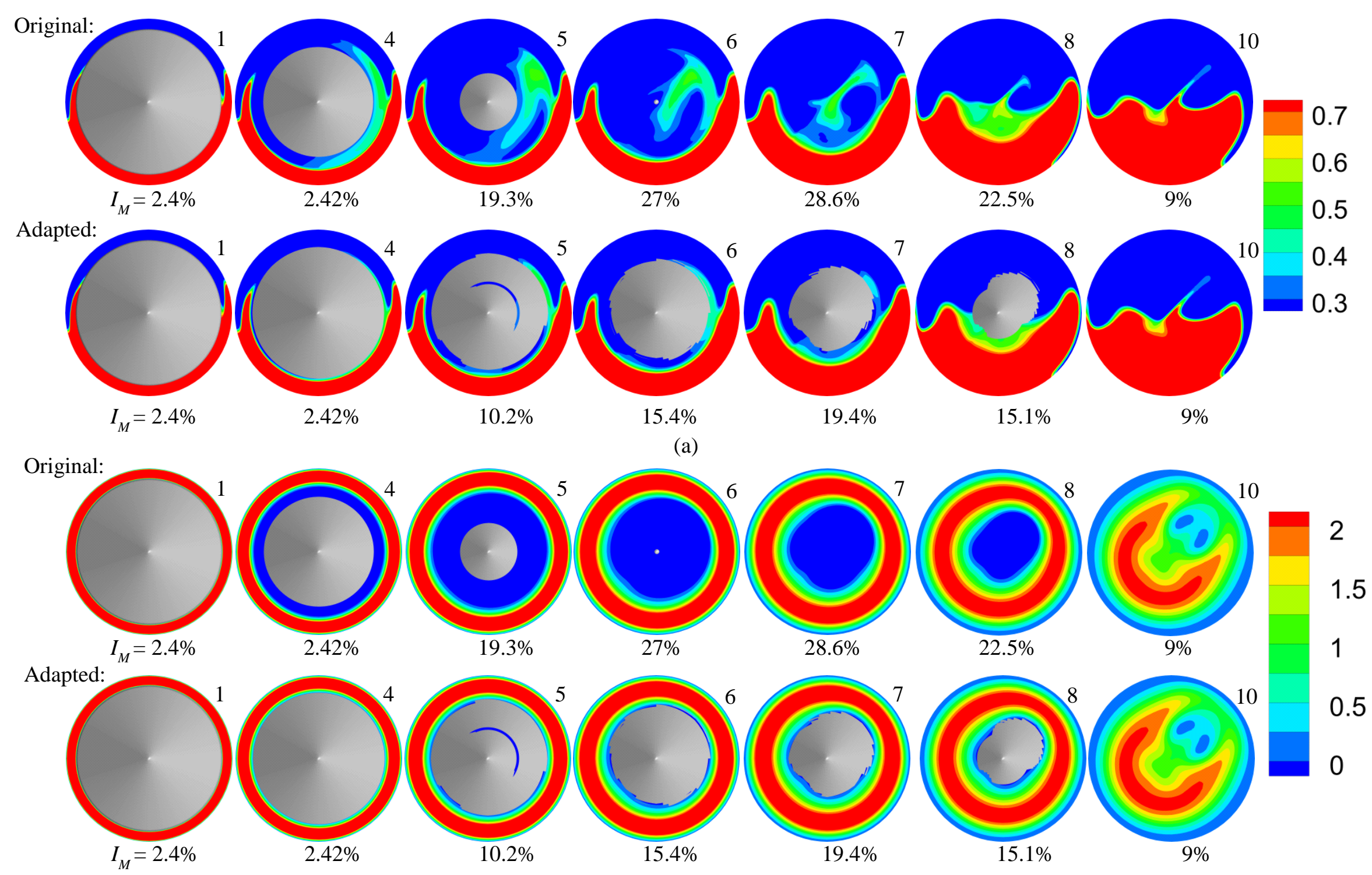

Figure 13: Contours of flow parameters on different selected sections of the original and adapted designs. (a) Volume fraction; (b) Nondimensional $\mathrm{X}$-velocity using inlet velocity as reference. 

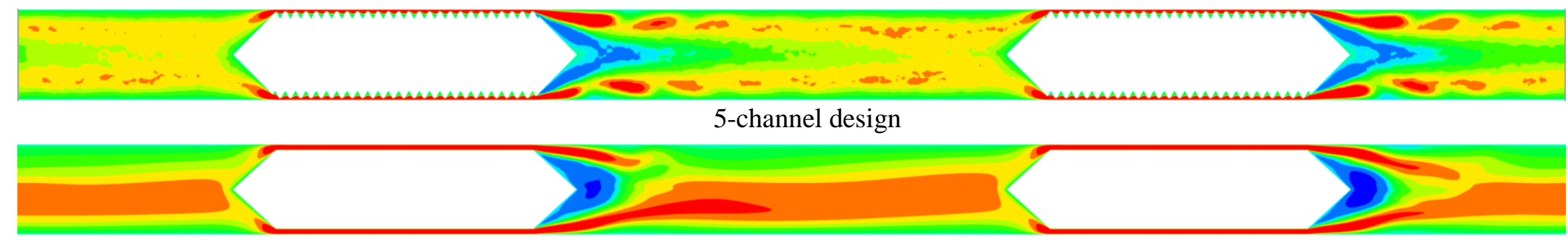

Smooth surface (no threading)

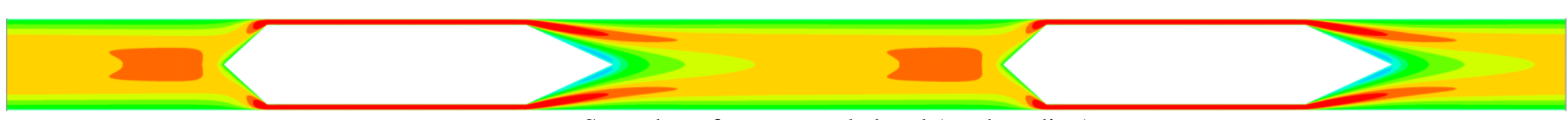

Smooth surface - extended end (no threading)

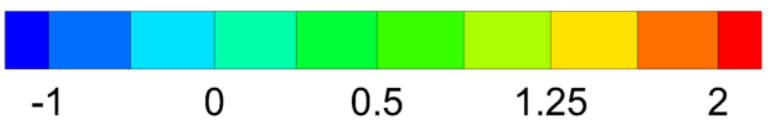

(a)

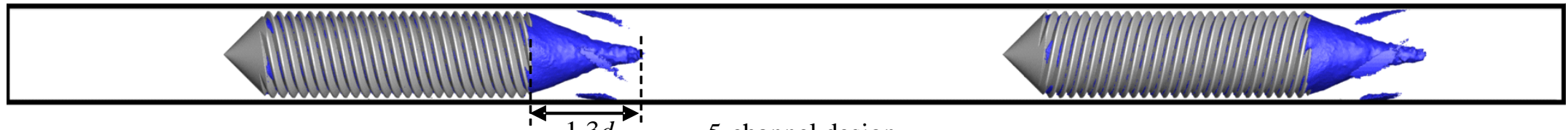

5-channel design

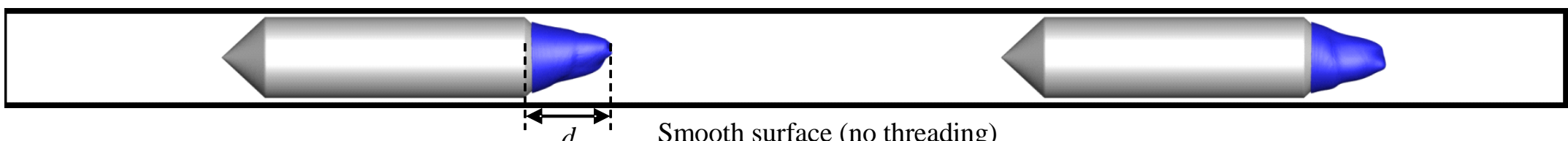

Smooth surface (no threading)

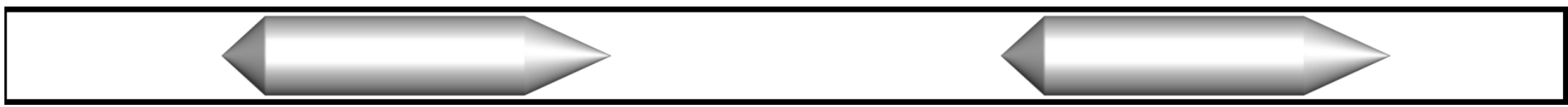

Smooth surface - extended end (no threading)

(b)

Figure 14: Overcoming the negative velocity region aft the inserts by increasing the length of the conical end $(R e=400)$. (a) Non-dimensional Xvelocity contour on axial plane using inlet velocity; (b) Negative velocity region generated aft of the inserts using iso-surface of X-velocity $\left(-0.000 v_{x}\right)$ 


\subsection{Applications as intensified tubular reactor}

There is an increasing trend to develop and use intensified tubular reactors for carrying out variety of reactions, particularly relevant to fine and specialty chemicals. ${ }^{1,78}$ A large number of reactor/mixer designs are introduced every year for a variety of industrial applications. ${ }^{5,79,80}$ For such reactor applications, it is essential to simultaneously realize enhanced mixing and heat transfer to intensify reactions. To examine such a simultaneous enhancement, intensity of mixing $\left(I_{M}\right)$ is compared with the heat transfer enhancement ratio $(\eta)$ in Figure 15. The heat transfer enhancement ratio $(\eta)$ evaluates both heat transfer and energy losses. The three channel configurations viz., 5-channel, 7-channel and 9-channel designs have been exhibited along with linear fit curves to indicate the corresponding Reynolds numbers. Conventional designs from literature as discussed in Figure 8 and Figure 11b, lie in the grey shaded region of the plot.

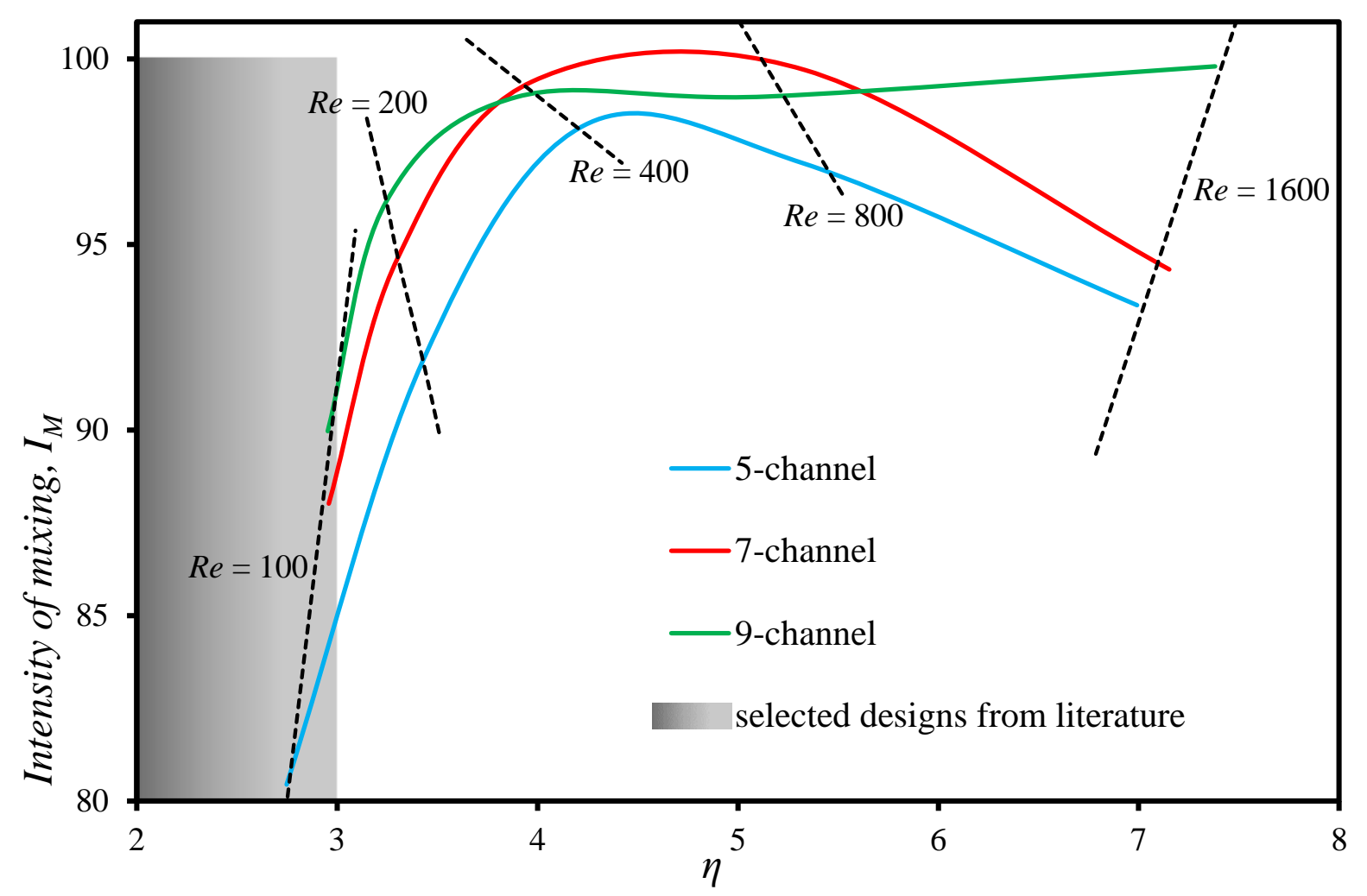

Figure 15: Comparison of heat transfer enhancement ratio $(\eta)$ with the corresponding Intensity of mixing percentage $\left(I_{M}\right)$

5-channel design — Present study, 7-channel design — Present study, 9-channel design — Present study, Selected designs from literature : Zig-Zag (semicircular) - Yoon et al. ${ }^{33}$; Serpentine (square) Karale et al. ${ }^{34}$; Coiled flow Inverter (circular) - Kumar et al. ${ }^{35}$; Pinched tube (circular) - Hasabnis et al. 25; Spirally corrugated tube - Kareem et al. ${ }^{44}$; Punched vortex generator - Zhang et al. ${ }^{55}$; Triangular obstruction - Khalde et al. ${ }^{56}$; Theoretical (pipe) - Shah and London ${ }^{70}$

Note: some of the selected designs have $I_{M}$ values below $80 \%$ too. Y-axis has been bounded to have a zoomed view. 
From Figure $8 \mathrm{~b}$, we observed that $\eta$ value is below 3 for all the considered devices from the literature. Also, from the literature, it has been observed that mixing intensity percentage above $90 \%$ is acceptable for most of the passive mixer applications as discussed previously. ${ }^{5}$ We observe from Figure 15 that the proposed mixer design offers high heat transfer for the same power input and mixing intensity and therefore offers an attractive platform for realizing modular, agile, intensified and continuous (MAGIC) reactors. ${ }^{1}$

\section{Conclusions}

A detailed computational study was carried out on screw inserts capable of enhancing shearing and diffusion by modifying the cross-sectional area and bends, and split-recombine of the flow streams. The influence of various parameters of threaded inserts was computationally investigated. The proposed threaded inserts provide a compact, easy to fabricate, low maintenance, and easily scalable mixer cum reactor. The design also offers adequate degrees of freedom to tailor the flow, mixing and heat transfer characteristics. Specific conclusions from this study may be summarized as:

- The threaded inserts split the fluid stream into two components viz., a stream flowing through the threading and another flowing through the annulus generated between insert and pipe. The interactions between these fluid streams components ensure higher heat and momentum transfer between them.

- Decreasing the number of channels on threaded inserts results in higher heat transfer effect (high $\mathrm{Nu}$ ) due to increased fluid surface contact region as fluid follows the channel path.

- For threaded inserts, as the numbers of channels are increased, the deviation of the flow from the axial direction decreases, thereby resulting in less energy loss.

- Enhanced mixing is achieved mainly due to the following reasons: i) swirling flow generated by threading, ii) pinching and expansion effect in the cone-cone ends region of the inserts and iii) direction reversal of flow due to switching of the direction of inserts threading ensured complete mixing.

- Decreasing the cone angle of the conical end aft results in avoidance of separation (from $90^{\circ}$ to $60^{\circ}$ ), thereby ensuring smooth unidirectional flow without forming any secondary vortices.

- Heat transfer enhancement ratio $(\eta)$ a parameter which evaluates heat transfer capability for same pumping power was observed to be higher for threaded inserts than selected conventional passive mixers/reactors and satisfying the requirement of mixing intensity.

- A small increase in the clearance between the insert and the pipe, results in a significant reduction of energy dissipation. For the studied geometry of the insert, an increase in clearance by $0.6 \mathrm{~mm}$ resulted in pressure loss reduction by $46 \%$. 
- $\quad$ Threaded inserts could achieve excellent mixing (>99\% of mixing intensity) and heat transfer (7 times of smooth inserts and more than 20 times without inserts).

The study on different geometric and flow parameters was carried out on the proposed passive mixer-cumreactor design, with the primary objective of enhancing mixing and heat transfer and was successfully achieved. A significant local pressure drop is observed in the threaded region of the mixer-cum reactor. The length, $L_{t}$ of the threaded part of the insert (Table 1), distance between two threaded inserts and the clearance between the pipe and the insert, has not yet been optimized.

\section{NOMENCLATURE}

\begin{tabular}{ll}
$A$ & Total area of specified region or elemental cell $\left(\mathrm{m}^{2}\right)$ \\
$A_{W}$ & Total area of surfaces in contact with fluid $\left(\mathrm{m}^{2}\right)$ \\
$A_{H}$ & Heated pipe wall area $\left(\mathrm{m}^{2}\right)$ \\
$A_{\text {inlet }}$ & Area of the inlet $\left(\mathrm{m}^{2}\right)$ \\
$c$ & Clearance between the insert and pipe $(\mathrm{m})$ \\
$C_{P}$ & Specific heat of the fluid at constant pressure $(\mathrm{Nm} / \mathrm{kg} . \mathrm{K})$ \\
$d$ & Total diameter of the insert $(\mathrm{m})$ \\
$D_{H}$ & Hydraulic diameter based on volume of the system $(\mathrm{m})$ \\
$D_{i m}$ & Mass diffusivity of the mixture of species $i$ (in suffix) $\left(\mathrm{m}^{2} / \mathrm{s}\right)$ \\
$d_{m}$ & Mean diameter of the insert $(\mathrm{m})$ \\
$d_{t}$ & Internal diameter of the pipe $(\mathrm{m})$ \\
$E$ & Total energy per unit mass $(\mathrm{Nm} / \mathrm{kg})$ \\
$f$ & Frictional factor \\
$h_{a v g}$ & Average convective heat transfer coefficient $\left(\mathrm{W} / \mathrm{m}^{2} . \mathrm{K}\right)$ \\
$i$ & species \\
$I_{M}$ & Intensity of mixing \\
$k$ & Thermal conductivity $(\mathrm{W} / \mathrm{m} . \mathrm{K})$ \\
$l$ & Axial advance of thread for one complete turn of $360^{\circ}(\mathrm{m})$ \\
$L_{t}$ & Length of the threaded part of the insert $(\mathrm{m})$ \\
$L_{i}$ & Length of the insert $(\mathrm{m})$ \\
$L_{M}$ & Distance between two consecutive insert units $(\mathrm{m})$ \\
$L$ & Total length of the considered periodic pipe domain $(\mathrm{m})$ \\
$L_{D}$ & Half periodic domain, i.e., pipe consisting of a single insert $(\mathrm{m})$ \\
$\dot{m}$ & Mass flow rate $(\mathrm{kg} / \mathrm{s})$ \\
$\bar{m}$ & Average mass fraction $(\mathrm{kg} / \mathrm{kg})$ of the reference surface $(\mathrm{m})$ \\
$m_{i}$ & Mass ratio of species $i(\mathrm{~kg} / \mathrm{kg})$ \\
$M$ & Mass of the liquid contained within the reactor $/ \mathrm{mixer}(\mathrm{kg})$ \\
$n$ & Number of threads $/ \mathrm{channels}$ on multi-threaded insert \\
$N u$ & Nusselt number \\
$R e$ & Reynolds number \\
$p$ & Pitch or width of the thread $(\mathrm{m})$ \\
$P$ & Static pressure $\left(\mathrm{N} / \mathrm{m}^{2}\right)$ \\
$P r$ & Prandtl number \\
$r, \theta, z$ & Cylindrical coordinates \\
$q$ & Volume flow rate of the fluid through the reactor $/ \mathrm{mixer}\left(\mathrm{m}^{3} / \mathrm{s}\right)$ \\
$\dot{Q}$ & Heat input or output to fluid through walls $(\mathrm{Nm} / \mathrm{s})$ \\
& \\
\hline &
\end{tabular}




$\begin{array}{ll}R e & \text { Reynolds number } \\ t & \text { Depth of the thread/channel }(\mathrm{m}) \\ T & \text { Temperature }(K) \\ T_{i n}, T_{\text {out }} & \text { Fluid temperature at the inlet and outlet }(K) \\ \Delta T_{L M T D} & \text { Logarithmic mean temperature difference }(K) \\ T_{W} & \text { Wall temperature }(K) \\ \boldsymbol{u} & \text { Velocity vector }(\mathrm{m} / \mathrm{s}) \\ u_{H} & \text { Superficial velocity of fluid based on hydraulic diameter }(\mathrm{m} / \mathrm{s}) \\ u_{\text {inlet }} & \text { Inlet velocity into the reactor based on the inlet diameter and mass flow rate } \\ v_{i} & \text { Velocity tensor with suffix ' } i \text { ' being the direction of the tensor }(\mathrm{m} / \mathrm{s}) \\ v_{p} & \text { Velocity of the fluid in pipe }(\mathrm{m} / \mathrm{s}) \\ V_{R} & \text { Total volume of the mixer/reactor unit consisting of two inserts }\left(\mathrm{m}^{3}\right) \\ w_{t} & \text { Distance between consecutive thread/channels }(\mathrm{m})\end{array}$

\section{Greek Letters}

$\begin{array}{ll}\varepsilon & \text { Energy dissipation rate per unit mass }\left(\mathrm{m}^{2} / \mathrm{s}^{3}\right) \\ \eta & \text { Heat transfer enhancement ratio } \\ \mu & \text { Dynamic viscosity }(\mathrm{kg} / \mathrm{m} . \mathrm{s}) \\ \vartheta & \text { Kinematic viscosity }\left(\mathrm{m}^{2} / \mathrm{s}\right) \\ \rho & \text { Density }\left(\mathrm{kg} / \mathrm{m}^{3}\right) \\ \sigma^{2} & \text { Variance }\left(\mathrm{kg}^{2}\right) \\ \tau & \text { Space-time of the fluid in the oscillator }(\mathrm{s}) \\ \overline{\bar{\tau}} & \text { Stress tensor }\left(\mathrm{N} / \mathrm{m}^{2}\right) \\ \phi & \text { Angle made by the V-thread (in degrees) } \\ \varphi & \text { Angle of the thread with respect to pipe axis (in degrees) } \\ \psi & \text { Cone angle of the ends of the insert (in degrees) }\end{array}$

\section{Supporting information:}

The Supplementary Information has the following figures:

Figure S1: 3D unstructured grid images for 9-channel design exhibiting the cut planes at different critical regions of the domain

Figure S2: CAD design and the generated grid of 5-channel design reactor at $R e=800$ with inserts Figure S3: Grid independency studyfor 5- channel design: Variation in pressure drop for different grid sizes at $R e=800$

Figure S4: Grid independency study for 5- channel design: Velocity variation along the radial distance normal to the axis of the pipe at $x / L_{D}=0.54$ for different grid sizes at $R e=800$

Figure S5a: Different configurations of threaded cone-cone inserts of manufactured using conventional lathe machine

Figure S5b: Experimental Setup for measuring pressure drop for the 5-channel passive mixer 
Figure S6: Comparison of Euler number $(E u)$ obtained from CFD and experiments for 5-channel design

Figure S7: Path lines drawn around the stud and shown from different viewpoints for 5 -channel design reactor at $\mathrm{Re}=800$

Figure S8a: Stream traces exhibiting the tracer mass fraction for 7-channel and 9-channel design at different Re

Figure S9a: Mixing intensity $\left(I_{M}\right)$ variation along the length for 5-channel and 9 channel design with $R e$.

Supplementary Information also describes the fabrication of inserts and tube as well as experimental methodology.

\section{References}

(1) Ranade, V. V.; Sharma, M. K.; Kulkarni, A. A. CRE for MAGIC (Modular, Agile, Intensified \& Continuous) Processes. Chem. Eng. J. 2015, 278, 454-468.

https://doi.org/10.1016/j.cej.2014.12.050.

(2) Utikar, R. P.; Ranade, V. V. Intensifying Multiphase Reactions and Reactors: Strategies and Examples. ACS Sustain. Chem. Eng. 2017, 5 (5), 3607-3622.

https://doi.org/10.1021/acssuschemeng.6b03017.

(3) Hessel, V.; Löwe, H.; Schönfeld, F. Micromixers - a Review on Passive and Active Mixing Principles. Chem. Eng. Sci. 2005, 60 (8-9), 2479-2501. https://doi.org/10.1016/j.ces.2004.11.033.

(4) Mansur, E. A.; YE, M.; Wang, Y.; Dai, Y. A State-of-the-Art Review of Mixing in Microfluidic Mixers. Chinese J. Chem. Eng. 2008, 16 (4), 503-516. https://doi.org/10.1016/S10049541(08)60114-7.

(5) Lee, C. Y.; Wang, W. T.; Liu, C. C.; Fu, L. M. Passive Mixers in Microfluidic Systems: A Review. Chem. Eng. J. 2016, 288, 146-160. https://doi.org/10.1016/j.cej.2015.10.122.

(6) Dinh, T. X.; Ogami, Y. Multieffects on Mixing Quality in an Active Micromixer. In Proceedings of FEDSM2007; ASME: San Diego, California USA, 2007; pp 1-10. https://doi.org/10.1115/FEDSM2007-37155.

(7) Huang, K. R.; Chang, J. S.; Chao, S. D.; Wung, T. S.; Wu, K. C. Study of Active Micromixer Driven by Electrothermal Force. Jpn. J. Appl. Phys. 2012, 51 (4 PART 1). https://doi.org/10.1143/JJAP.51.047002.

(8) Khatavkar, V. V.; Anderson, P. D.; den Toonder, J. M. J.; Meijer, H. E. H. Active Micromixer Based on Artificial Cilia. Phys. Fluids 2007, 19 (8), 083605-1. https://doi.org/10.1063/1.2762206.

(9) Kunti, G.; Bhattacharya, A.; Chakraborty, S. Rapid Mixing with High-Throughput in a SemiActive Semi-Passive Micromixer. Electrophoresis 2017, 38 (9-10), 1310-1317. https://doi.org/10.1002/elps.201600393.

(10) Park, S. J.; Kim, J. K.; Park, J.; Chung, S.; Chung, C.; Chang, J. K. Rapid Three-Dimensional Passive Rotation Micromixer Using the Breakup Process. J. Micromechanics Microengineering 2004, 14 (1), 6-14. https://doi.org/10.1088/0960-1317/14/1/302.

(11) Yang, Z.; Goto, H.; Matsumoto, M.; Maeda, R. Active Micromixer for Microfluidic Systems Using Lead-Zirconate-Titanate (PZT)-Generated Ultrasonic Vibration. Electrophoresis 2000, 21 (1), 116-119. https://doi.org/10.1002/(SICI)1522-2683(20000101)21:1<116::AIDELPS116>3.0.CO;2-Y.

(12) Yu, S.; Jeon, T. J.; Kim, S. M. Active Micromixer Using Electrokinetic Effects in the Micro/Nanochannel Junction. Chem. Eng. J. 2012, 197, 289-294. https://doi.org/10.1016/j.cej.2012.05.044.

(13) Thakur, R. K.; Vial, C.; Nigam, K. D. P.; Nauman, E. B.; Djelveh, G. Static Mixers in the Process 
Industries-A Review. Chem. Eng. Res. Des. 2003, 81 (7), 787-826.

https://doi.org/10.1205/026387603322302968.

(14) Nguyen, N. T.; Wu, Z. Micromixers - A Review. J. Micromechanics Microengineering 2005, 15 (2), R1-R16. https://doi.org/10.1088/0960-1317/15/2/R01.

(15) Hessel, V.; Knobloch, C.; Lowe, H. Review on Patents in Microreactor and Micro Process Engineering. Recent Patents Chem. Eng. 2008, 1 (1), 1-16.

https://doi.org/10.2174/2211334710801010001.

(16) Lee, C. Y.; Chang, C. L.; Wang, Y. N.; Fu, L. M. Microfluidic Mixing: A Review. Int. J. Mol. Sci. 2011, 12 (5), 3263-3287. https://doi.org/10.3390/ijms12053263.

(17) Yao, X.; Zhang, Y.; Du, L.; Liu, J.; Yao, J. Review of the Applications of Microreactors. Renew. Sustain. Energy Rev. 2015, 47, 519-539. https://doi.org/10.1016/j.rser.2015.03.078.

(18) Haase, S.; Murzin, D. Y.; Salmi, T. Review on Hydrodynamics and Mass Transfer in Minichannel Wall Reactors with Gas-Liquid Taylor Flow. Chem. Eng. Res. Des. 2016, 113, 304-329. https://doi.org/10.1016/j.cherd.2016.06.017.

(19) Zhang, J.; Wang, K.; Teixeira, A. R.; Jensen, K. F.; Luo, G. Design and Scaling up of Microchemical Systems: A Review. Annu. Rev. Chem. Biomol. Eng. 2017, 8 (1), 285-305. https://doi.org/10.1146/annurev-chembioeng-060816-101443.

(20) Fletcher, P. D. I.; Haswell, S. J.; Pombo-Villar, E.; Warrington, B. H.; Watts, P.; Wong, S. Y. F.; Zhang, X. Micro Reactors: Principles and Applications in Organic Synthesis. Tetrahedron 2002, 58 (24), 4735-4757. https://doi.org/10.1016/S0040-4020(02)00432-5.

(21) Hardt, S.; Drese, K. S.; Hessel, V.; Schönfeld, F. Passive Micromixers for Applications in the Microreactor and MTAS Fields. Microfluid. Nanofluidics 2005, 1 (2), 108-118. https://doi.org/10.1007/s10404-004-0029-0.

(22) Löb, P.; Hessel, V.; Hensel, A.; Simoncelli, A. Micromixer Based Liquid/Liquid-Dispersion in the Context of Consumer Good Production with Focus on Surfactant Vesicle Formation. Chim. Oggi 2008, 26 (1 SUPPL. COMP.), 30-32.

(23) Pennella, F.; Rossi, M.; Ripandelli, S.; Rasponi, M.; Mastrangelo, F.; Deriu, M. A.; Ridolfi, L.; Kähler, C. J.; Morbiducci, U. Numerical and Experimental Characterization of a Novel Modular Passive Micromixer. Biomed. Microdevices 2012, 14 (5), 849-862. https://doi.org/10.1007/s10544-012-9665-4.

(24) Pennemann, H.; Hardt, S.; Hessel, V.; Lob, P.; Weise, F. Micromixer Based Liquid/Liquid Dispersion. Chem. Eng. Technol. 2005, 28 (4), 501-508. https://doi.org/10.1002/ceat.200407144.

(25) Hasabnis, N. S.; Totlani, K. A.; Ranade, V. V. Heat Transfer and Mixing in Flow through Pinched Pipe. Can. J. Chem. Eng. 2015, 93 (10), 1860-1868. https://doi.org/10.1002/cjce.22275.

(26) Afzal, A.; Kim, K.-Y. Performance Evaluation of Three Types of Passive Micromixer with Convergent-Divergent Sinusoidal Walls. J. Mar. Sci. Technol. 2014, 22 (6), 680-686. https://doi.org/10.6119/JMST-014-0321-2.

(27) Bhagat, A. A. S.; Peterson, E. T. K.; Papautsky, I. A Passive Planar Micromixer with Obstructions for Mixing at Low Reynolds Numbers. J. Micromechanics Microengineering 2007, 17 (5), 10171024. https://doi.org/10.1088/0960-1317/17/5/023.

(28) Cook, K.; Fan, Y.; Hassan, I. Experimental Investigation of a Scaled-up Passive Interdigital Micromixer with Circular-Sector Mixing Elements. In 8th Thermal Engineering Joint Conference; ASME: Honolulu, Hawaii, USA, 2011; pp T10118-T10118-6. https://doi.org/10.1115/AJTEC2011-44064.

(29) Cook, K. J.; Fan, Y.; Hassan, I. Mixing Evaluation of a Passive Scaled-up Serpentine Micromixer with Slanted Grooves. J. Fluids Eng. 2013, 135 (8), 081102.1-081102.12. https://doi.org/10.1115/1.4024146.

(30) Lee, N. Y.; Yamada, M.; Seki, M. Development of a Passive Micromixer Based on Repeated Fluid Twisting and Flattening, and Its Application to DNA Purification. Anal. Bioanal. Chem. 2005, 383 (5), 776-782. https://doi.org/10.1007/s00216-005-0073-y.

(31) Shim, J. S.; Nikcevic, I.; Rust, M. J.; Bhagat, A. A. S.; Heineman, W. R.; Seliskar, C. J.; Ahn, C. 
H.; Papautsky, I. Simple Passive Micromixer Using Recombinant Multiple Flow Streams. Proc. SPIE - Int. Soc. Opt. Eng. 2007, 6465 (January), 1-8. https://doi.org/10.1117/12.701977.

(32) Khalde, C. M.; Sangwai, J. S.; Ranade, V. V. Methods and Apparatus for Passive Mixing of Multiphase Fluids. IN201841014253; PCT/IN2019/050226-IITM-010500WO, 2018.

(33) Yoon, S.-J.; O’Brien, J.; Chen, M.; Sabharwall, P.; Sun, X. Development and Validation of Nusselt Number and Friction Factor Correlations for Laminar Flow in Semi-Circular Zigzag Channel of Printed Circuit Heat Exchanger. Appl. Therm. Eng. 2017, 123, 1327-1344. https://doi.org/10.1016/j.applthermaleng.2017.05.135.

(34) Karale, C. M.; Bhagwat, S. S.; Ranade, V. V. Flow and Heat Transfer in Serpentine Channels. AIChE J. 2013, 59 (5), 1814-1827. https://doi.org/10.1002/aic.13954.

(35) Kumar, V.; Mridha, M.; Gupta, A. K.; Nigam, K. D. P. Coiled Flow Inverter as a Heat Exchanger. Chem. Eng. Sci. 2007, 62 (9), 2386-2396. https://doi.org/10.1016/j.ces.2007.01.032.

(36) Singh, J.; Montesinos-Castellanos, A.; Nigam, K. D. P. Thermal and Hydrodynamic Performance of a Novel Passive Mixer 'Wavering Coiled Flow Inverter.' Chem. Eng. Process. - Process Intensif. 2019, 141 (January), 107536. https://doi.org/10.1016/j.cep.2019.107536.

(37) Wang, H.; Shi, L.; Zhou, T.; Xu, C.; Deng, Y. A Novel Passive Micromixer with Modified Asymmetric Lateral Wall Structures. Asia-Pacific J. Chem. Eng. 2018, 13 (3), e2202. https://doi.org/10.1002/apj.2202.

(38) Sharma, M. K.; Potdar, S. B.; Kulkarni, A. A. Pinched Tube Flow Reactor: Hydrodynamics and Suitability for Exothermic Multiphase Reactions. AIChE J. 2017, 63 (1), 358-365. https://doi.org/10.1002/aic.15498.

(39) Vicente, P. G.; García, A.; Viedma, A. Experimental Investigation on Heat Transfer and Frictional Characteristics of Spirally Corrugated Tubes in Turbulent Flow at Different Prandtl Numbers. Int. J. Heat Mass Transf. 2004, 47 (4), 671-681. https://doi.org/10.1016/j.ijheatmasstransfer.2003.08.005.

(40) Sparrow, E. M.; Prata, A. T. Numerical Solutions for Laminar Flow and Heat Transfer in a Periodically Converging-Diverging Tube, with Experimental Confirmation. Numer. Heat Transf. 1983, 6 (4), 441-461. https://doi.org/10.1080/01495728308963099.

(41) Prata, A. T.; Sparrow, E. M. Heat Transfer and Fluid Flow Characteristics for an Annulus of Periodically Varying Cross Section. Numer. Heat Transf. 1984, 7 (3), 285-304. https://doi.org/10.1080/01495728408961826.

(42) Rafeie, M.; Welleweerd, M.; Hassanzadeh-Barforoushi, A.; Asadnia, M.; Olthuis, W.; Warkiani, M. E. An Easily Fabricated Three-Dimensional Threaded Lemniscate-Shaped Micromixer for a Wide Range of Flow Rates. Biomicrofluidics 2017, 11 (1). https://doi.org/10.1063/1.4974904.

(43) Van Cauwenberge, D. J.; Dedeyne, J. N.; Van Geem, K. M.; Marin, G. B.; Floré, J. Numerical and Experimental Evaluation of Heat Transfer in Helically Corrugated Tubes. AIChE J. 2018, 64 (5), 1702-1713. https://doi.org/10.1002/aic.16038.

(44) Kareem, Z. S.; Mohd Jaafar, M. N.; Lazim, T. M.; Abdullah, S.; Abdulwahid, A. F. Heat Transfer Enhancement in Two-Start Spirally Corrugated Tube. Alexandria Eng. J. 2015, 54 (3), 415-422. https://doi.org/10.1016/j.aej.2015.04.001.

(45) Costa, M. F.; Fonte, C. M.; Dias, M. M.; Lopes, J. C. B. Heat Transfer Performance of NETmix-A Novel Micro-Meso Structured Mixer and Reactor. AIChE J. 2017, 63 (6), 2496-2508. https://doi.org/10.1002/aic.15728.

(46) Li, J.; Xia, G.; Li, Y. Numerical and Experimental Analyses of Planar Asymmetric Split-andRecombine Micromixer with Dislocation Sub-Channels. J. Chem. Technol. Biotechnol. 2013, 88 (9), 1757-1765. https://doi.org/10.1002/jctb.4044.

(47) Viktorov, V.; Mahmud, M. R.; Visconte, C. Numerical Study of Fluid Mixing at Different Inlet Flow-Rate Ratios in Tear-Drop and Chain Micromixers Compared to a New H-C Passive Micromixer. Eng. Appl. Comput. Fluid Mech. 2016, 10 (1), 182-192. https://doi.org/10.1080/19942060.2016.1140075.

(48) Viktorov, V.; Nimafar, M. A Novel Generation of 3D SAR-Based Passive Micromixer: Efficient 
Mixing and Low Pressure Drop at a Low Reynolds Number. J. Micromechanics Microengineering 2013, 23 (5), 055023. https://doi.org/10.1088/0960-1317/23/5/055023.

(49) Hermann, P.; Timmermann, J.; Hoffmann, M.; Schlüter, M.; Hofmann, C.; Löb, P.; Ziegenbalg, D. Optimization of a Split and Recombine Micromixer by Improved Exploitation of Secondary

Flows. Chem. Eng. J. 2018, 334 (May 2017), 1996-2003.

https://doi.org/10.1016/j.cej.2017.11.131.

(50) Schönfeld, F.; Hessel, V.; Hofmann, C. An Optimised Split-and-Recombine Micro-Mixer with Uniform 'Chaotic' Mixing. Lab Chip 2004, 4 (1), 65-69. https://doi.org/10.1039/B310802C.

(51) Calabrese, G. S.; Pissavini, S. From Batch to Continuous Flow Processing in Chemicals Manufacturing. AIChE J. 2011, 57 (4), 828-834. https://doi.org/10.1002/aic.12598.

(52) Nieves-Remacha, M. J.; Kulkarni, A. A.; Jensen, K. F. Gas-Liquid Flow and Mass Transfer in an Advanced-Flow Reactor. Ind. Eng. Chem. Res. 2013, 52 (26), 8996-9010.

https://doi.org/10.1021/ie4011707.

(53) Nieves-Remacha, M. J.; Kulkarni, A. A.; Jensen, K. F. Hydrodynamics of Liquid-Liquid Dispersion in an Advanced-Flow Reactor. Ind. Eng. Chem. Res. 2012, 51 (50), 16251-16262. https://doi.org/10.1021/ie301821k.

(54) Kanaris, A.; Mouza, A. Design of a Novel $\mu$-Mixer. Fluids 2018, 3 (1), 10. https://doi.org/10.3390/fluids3010010.

(55) Zhang, T.; Huang, Z. Q.; Zhang, X. B.; Liu, C. J. Numerical Investigation of Heat Transfer Using a Novel Punched Vortex Generator. Numer. Heat Transf. Part A Appl. 2016, 69 (10), 1150-1168. https://doi.org/10.1080/10407782.2015.1125724.

(56) Khalde, C. M.; Kulkarni, A. A.; Ranade, V. V. CFD Simulations of Axial Mixing in AMAR Micro-Mixer Cum Reactor. In 15th European Conference on Mixing (St. Petersburg, 2015); Saint Petersburg, 2015; pp 187-192.

(57) Jung, S. Y.; Ahn, K. H.; Kang, T. G.; Park, G. T.; Kim, S. U. Chaotic Mixing in a BarrierEmbedded Partitioned Pipe Mixer. AIChE J. 2018, 64 (2), 717-729. https://doi.org/10.1002/aic.15929.

(58) Stec, M.; Synowiec, P. M. Study of Fluid Dynamic Conditions in the Selected Static Mixers Part III-Research of Mixture Homogeneity. Can. J. Chem. Eng. 2019, 97 (4), 995-1007. https://doi.org/10.1002/cjce.23290.

(59) Sangwai, J. S.; Khalde, C. M. Apparatus for Measuring Rheological Parameters and Methods for Its Operation. US 9958367 B2, 2018.

(60) Pandey, G.; Linga, P.; Sangwai, J. S. High Pressure Rheology of Gas Hydrate Formed from Multiphase Systems Using Modified Couette Rheometer. Rev. Sci. Instrum. 2017, 88 (2), 025102. https://doi.org/10.1063/1.4974750.

(61) National Bureau of Standards. Screw-Thread Standards for Federal Services; Washington DC, 1960. https://doi.org/AD-A279 290.

(62) Ranade, V. V. Computational Flow Modelling for Chemical Reactor Engineering, 1st ed.; Academic Press, 2002.

(63) Webb, R. L.; Kim, N.-H. Principles of Enhanced Heat Transfer, Second Edi.; Webb, R. L., Kim, N.-H., Eds.; Taylor \& Francis Group: Great Britain, 2005.

(64) Saha, S. K.; Ranjan, H.; Emani, M. S.; Bharti, A. K. Performance Evaluation Criteria in Heat Transfer Enhancement. In Thermal Engineering and Applied Science; Kulacki, F., Ed.; SpringerBriefs in Applied Sciences and Technology; Springer International Publishing: Cham, Switzerland, 2020; pp 7-28. https://doi.org/10.1007/978-3-030-20758-8.

(65) Bhuiya, M. M. K.; Chowdhury, M. S. U.; Saha, M.; Islam, M. T. Heat Transfer and Friction Factor Characteristics in Turbulent Flow through a Tube Fitted with Perforated Twisted Tape Inserts. Int.

Commun. Heat Mass Transf. 2013, 46, 49-57.

https://doi.org/10.1016/j.icheatmasstransfer.2013.05.012.

(66) Eiamsa-ard, S.; Promvonge, P. Thermal Characteristics in Round Tube Fitted with Serrated Twisted Tape. Appl. Therm. Eng. 2010, 30 (13), 1673-1682. 
https://doi.org/10.1016/j.applthermaleng.2010.03.026.

(67) Ansys Inc. Theory Guide and User's Guide. Ansys Fluent: USA 2015.

(68) AutoCAD. User's Guide. Autodesk Inc 2013.

(69) Thompson, J. F.; Soni, B. K.; Weatherill, N. P. Handbook of Grid Generation, Taylor \& F.; 1998.

(70) Shah, R. K.; London, A. L. Circular Duct. In Laminar Flow Forced Convection in Ducts; Elsevier, 1978; Vol. 16, pp 78-152. https://doi.org/10.1016/B978-0-12-020051-1.50010-3.

(71) Singh, J.; Montesinos-Castellanos, A.; Nigam, K. D. P. Process Intensification for Compact and Micro Heat Exchangers through Innovative Technologies: A Review. Ind. Eng. Chem. Res. 2019, 58 (31), 13819-13847. https://doi.org/10.1021/acs.iecr.9b02082.

(72) Sheikholeslami, M.; Gorji-Bandpy, M.; Ganji, D. D. Review of Heat Transfer Enhancement Methods: Focus on Passive Methods Using Swirl Flow Devices. Renew. Sustain. Energy Rev. 2015, 49, 444-469. https://doi.org/10.1016/j.rser.2015.04.113.

(73) Levenspiel, O. Chemical Reaction Engineering. Ind. Eng. Chem. Res. 1999, 38 (11), 4140-4143. https://doi.org/10.1021/ie990488g.

(74) Solehati, N.; Bae, J.; Sasmito, A. P. Numerical Investigation of Mixing Performance in Microchannel T-Junction with Wavy Structure. Comput. Fluids 2014, 96, 10-19. https://doi.org/10.1016/j.compfluid.2014.03.003.

(75) Khalde, C. M.; Pandit, A. V; Sangwai, J. S.; Ranade, V. V. Flow, Mixing, and Heat Transfer in Fluidic Oscillators. Can. J. Chem. Eng. 2019, 97 (2), 542-559. https://doi.org/10.1002/cjce.23377.

(76) Xie, T.; Xu, C. Numerical and Experimental Investigations of Chaotic Mixing Behavior in an Oscillating Feedback Micromixer. Chem. Eng. Sci. 2017, 171, 303-317. https://doi.org/10.1016/j.ces.2017.05.040.

(77) Nieves-Remacha, M. J.; Kulkarni, A. A.; Jensen, K. F. OpenFOAM Computational Fluid Dynamic Simulations of Single-Phase Flows in an Advanced-Flow Reactor. Ind. Eng. Chem. Res. 2015, 54 (30), 7543-7553. https://doi.org/10.1021/acs.iecr.5b00232.

(78) Haber, J.; Kashid, M. N.; Renken, A.; Kiwi-Minsker, L. Heat Management in Single and MultiInjection Microstructured Reactors: Scaling Effects, Stability Analysis, and Role of Mixing. Ind. Eng. Chem. Res. 2012, 51 (4), 1474-1489. https://doi.org/10.1021/ie201158a.

(79) Ranade, V. V. Engineering Reactors for Catalytic Reactions. J. Chem. Sci. 2014, 126 (2), 341351. https://doi.org/10.1007/s12039-014-0589-9.

(80) Kumar, V.; Paraschivoiu, M.; Nigam, K. D. P. Single-Phase Fluid Flow and Mixing in Microchannels. Chem. Eng. Sci. 2011, 66 (7), 1329-1373.

https://doi.org/10.1016/j.ces.2010.08.016. 
Graphical abstract:

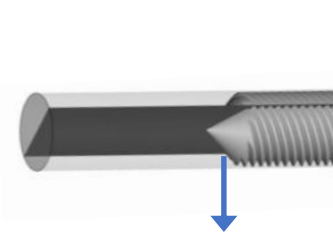

(1)

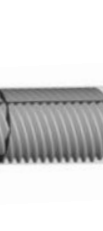

(1)

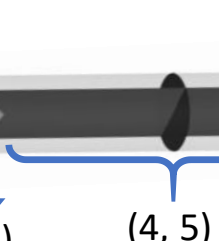

$(4,5)$

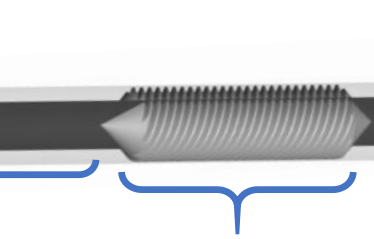

$(2,3)$

\section{Screw Inserts for Enhanced Mixing \& Heat Transfer}

(1) Pinching and expansion

(2) Shearing

(3) Curved channels

(4) Swirling

(5) Flow switching

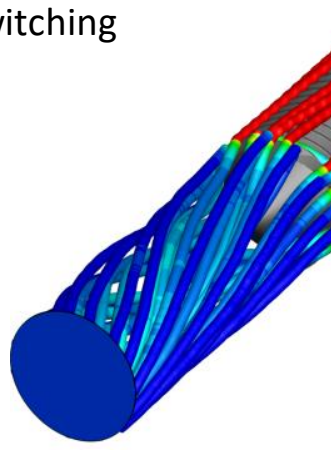

\section{Path lines}

Colored by Velocity Magnitude

Red: High; Blue: Low 